\title{
Contextos
}

\section{Reflexiones en torno a la enseñanza de la arquitectura y el urbanismo en Colombia.}

\section{Conversaciones con Juan Carlos Pérgolis Valsecchi, René Carrasco Rey y Juan Carlos del Castillo

\author{
Reflections on the teaching of architecture and urban planning in Colombia. Conversations with Juan \\ Carlos Pérgolis Valsecchi, René Carrasco Rey y Juan Carlos del Castillo
}

\section{Andrés Ávila-Gómez}

Université Paris I Panthéon-Sorbonne. París (Francia)

Ecole Doctorale 44I Histoire de l'Art

Ávila-Gómez, A. (202I). Reflexiones en torno a la enseñanza de la arquitectura y el urbanismo en Colombia: Conversaciones con Juan Carlos Pérgolis Valsecchi, René Carrasco Rey y Juan Carlos Del Castillo. Revista de Arquitectura (Bogotá), 23(I), 3-19. https://doi.org/10.14718/RevArq.202I.3850

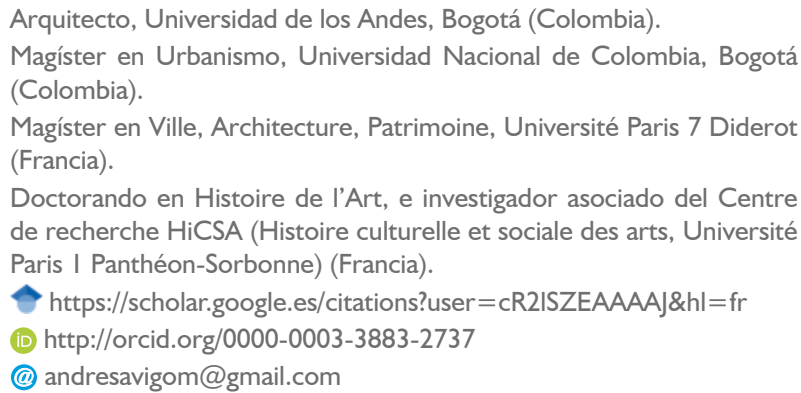

\section{Resumen}

La actual coyuntura social y económica, marcada por una pandemia, parece poner en evidencia la caducidad de ideas y estructuras con las cuales se ha enseñado desde el siglo $X X$. En ese sentido, la incertidumbre generada durante 2020 en el medio universitario en torno al futuro inmediato de la educación superior se debate entre el entusiasmo puesto por algunos sectores en las ventajas ofrecidas por las nuevas tecnologías y el escepticismo que otros sectores expresan respecto a lo que pueda resultar de la avalancha de transformaciones radicales en las formas como se transmite el conocimiento. En ese contexto, y específicamente en el caso colombiano, cabe reflexionar sobre un tema que hasta ahora ha sido tratado de manera aislada y bastante fragmentaria: la historia de la enseñanza de la arquitectura y el urbanismo a partir de la creación de la primera facultad de arquitectura, en el país, en 1936. Ante tales constataciones, y con el propósito de aportar nuevos elementos y perspectivas, se ha preparado una serie de entrevistas a arquitectos que durante el último medio siglo se han destacado en la esfera de la enseñanza de la arquitectura y el urbanismo en instituciones universitarias colombianas - y en algunos casos, también en el ámbito latinoamericano-. El interés se centra en indagar y profundizar en la reconstrucción de aquellos contextos culturales y pedagógicos que enmarcaron y condicionaron la formación recibida por los entrevistados durante su época como estudiantes en facultades de arquitectura de universidades colombianas y extranjeras. Al sondear la memoria de los protagonistas de esta historia, se espera que el presente texto pueda estimular el interés de nuevas generaciones de estudiantes e investigadores en el estudio y el conocimiento de la historia de la enseñanza de las profesiones aquí evocadas.

Palabras clave: Enseñanza profesional; escuelas de arquitectura; enseñanza de la arquitectura; contexto de aprendizaje; programa de estudios superiores

\section{Abstract}

The current social and economic situation, marked by a pandemic, seems to highlight the expiration of ideas and structures which have been used for teaching since the twentieth century. In this sense, the uncertainty generated during 2020 in the university milieu regarding the immediate future of higher education is debated between the enthusiasm of some sectors for the advantages offered by new technologies and the skepticism that other sectors express regarding what may result from the avalanche of radical transformations in the ways knowledge is transmitted. The current social and economic situation, marked by a pandemic, seems to highlight the expiration of ideas and structures which have been used for teaching since the twentieth century. In this sense, the uncertainty generated during 2020 in the university milieu regarding the immediate future of higher education is debated between the enthusiasm of some sectors for the advantages offered by new technologies and the skepticism that other sectors express regarding what may result from the avalanche of radical transformations in the ways knowledge is transmitted. In this context, and specifically in the Colombian case, it is worth reflecting on a topic that until now has been treated in an isolated and rather fragmentary manner: the history of the teaching of architecture and urban planning since the creation of the first faculty of architecture in the country in 1936. In view of these findings, and with the purpose of providing new elements and perspectives, a series of interviews has been prepared with architects who over the last half century have stood out in the field of architecture and urban planning teaching in Colombian universities, and in some cases, also in Latin American ones. The interest is focused on investigating and deepening the reconstruction of those cultural and pedagogical contexts that framed and conditioned the training received by the interviewees during their time as students in architecture faculties of Colombian and foreign universities. By probing the memory of the protagonists of this story, it is hoped that this text can stimulate the interest of new generations of students and researchers in the study and knowledge of the history of the teaching of the professions evoked here.

Keywords: Professional education; schools of architecture; architecture education; learning context; higher education curriculum

\section{Introducción}

Las restricciones impuestas a escala global desde el inicio de la crisis sanitaria — a finales de 2019 - han generado una compleja coyuntura social y económica, marcada por una pandemia - cuya evolución resulta cada vez más incierta en diferentes ámbitos. En el medio universitario, la implementación masiva de diversas transformaciones de orden pedagógico y tecnológico parece poner en evidencia la caducidad de ideas y estructuras con y dentro de las cuales se han enseñado desde el siglo XX disciplinas como la arquitectura y el urbanismo ${ }^{1}$. En este sentido, la incertidumbre generada durante 2020 en el medio universitario en torno al futuro inmediato de la educación superior se debate entre el entusiasmo puesto por algunos sectores en las ventajas ofrecidas por las nuevas tecnologías y las dinámicas colaborativas globales, y el escepticismo que otros sectores expresan respecto a lo que pueda resultar de la avalancha de transformaciones radicales en las formas como se solía transmitir el conocimiento.

Efectivamente en el caso colombiano, esta coyuntura se presenta como un momento propicio para reflexionar sobre un tema que hasta ahora ha sido tratado de manera aislada y bastante fragmentaria: la evolución de la enseñanza de la arquitectura y el urbanismo a partir de la creación de la primera facultad de arquitectura en Colombia, en 1936 (Angulo Flórez, 1986). Aunque extremadamente sucintos, los textos sobre

Ver la entrevista realizada en 2019 a Eva Franch i Gilabert sobre el caso específico de la Architectural Association School of Architecture. Franch i Gilabert es la primera mujer en ser nombrada directora de la AA, en 2018. (Bardí I Milà, B, García-Escudero, D., 2019) 
la historia de la enseñanza de la arquitectura, y del urbanismo, en la Universidad Nacional de Colombia, escritos respectivamente por Carlos Niño Murcia, Hans Rother Trenenfels y Manuel García Camacho, y publicados en el volumen especial preparado en 1986 para conmemorar el cincuentenario de la creación de la Facultad de Arquitectura (Angulo Flórez, 1986), constituyeron la primera aproximación importante en el medio colombiano. Pese a la existencia de algunos estudios y textos que desde finales del siglo XX han abordado aspectos ligados a instituciones y a actores destacados en ese campo, encontramos que la historiografía existente resulta aún escasa y dispersa —en sus contenidos y sus objetivos - como para que se pretenda emprender con ella un análisis global a semejanza de, por ejemplo, la obra colectiva dirigida por Joan Ockman que da cuenta del caso norteamericano $(2012)^{2}$. En esa misma línea de investigación, el caso colombiano amerita ser estudiado.

Por otra parte, se considera importante aprovechar el panorama actual en el medio académico latinoamericano -y más ampliamente, en el espacio hispanófono- en el que podemos verificar hoy por hoy un creciente interés en este tipo de estudios: como ejemplo de dicho fenómeno, podemos citar los números consagrados a estas temáticas por algunas revistas especializadas reconocidas como Zarch $^{3}$ (Universidad de Zaragoza) y Registros ${ }^{4}$ (Universidad Nacional de Mar del Plata), y algunos coloquios y foros que han propiciado la divulgación de investigaciones conexas, como sucedió en el $15^{\circ}$ Foro de Historia y Crítica de la Arquitectura Moderna, celebrado en 2017 en Nuevo León ${ }^{5}$; y el $1^{\circ}$ Seminario Internacional "Transferencias/Interferencias", celebrado en 2020 (Avila Gomez, Muñoz Lozano, Porraz Castillo, 2020).

\section{Metodología}

Ante las constataciones expuestas, y con el fin de aportar nuevos elementos y perspectivas que puedan alimentar específicamente el estudio del caso colombiano, se preparó una serie de entrevistas a personajes que se han destacado en la esfera de la enseñanza de la arquitectura y el urbanismo, en instituciones universitarias colombianas -y en algunos casos, también en el ám-

2 Se trata de: Architecture school. three centuries of educating architects in North America, con textos de Joan Ockman Dell Upton; Michael J. Lewis; Anthony Alofsin; Avigail Sachs; Mary McLeod; y Stan Allen.

3 Se trata del número titulado "El aprendizaje de la arquitectura" (No. 12), publicado en 2019. https://papiro.unizar.es/ojs/ index.php/zarch/issue/view/266

4 Se trata de los números titulados "Encrucijadas en la enseñanza de la arquitectura en América Latina en el siglo XX" (vol.16: No. 1 y No. 2), publicados en 2020. https://revistasfaud.mdp.edu.ar/registros/issue/view/30 y https://revistasfaud.mdp.edu.ar/registros/issue/view/38.

5 El tema central fue: "La historiografía de la arquitectura frente a dos responsabilidades: la formación del arquitecto y la conciencia social" bito latinoamericano-. En definitiva, el interés se centra en indagar y profundizar no tanto en la evocación de carreras individuales, sino en la reconstrucción de aquellos contextos culturales y pedagógicos que enmarcaron y condicionaron la formación ${ }^{6}$ recibida por los entrevistados durante su época como estudiantes en facultades de arquitectura de universidades colombianas y extranjeras. Los entrevistados invitados a esta serie nacieron entre 1940 y 1960, y realizaron sus estudios durante los años sesenta y setenta del siglo XX, con todo lo que ello implicó desde el punto de vista cultural y social: crecieron en medio del Frente Nacional en Colombia de los ecos de mayo del 68, de los militantismos en medio de la Guerra Fría, de los movimientos contraculturales, etc.

Así pues, para recoger los testimonios de actores que desde diversos campos (arquitectura, urbanismo, diseño, etc.) y a través de múltiples actividades (enseñanza, práctica profesional, crítica, etc.) han contribuido en los últimos 50 años no solo a la construcción de las ciudades colombianas, sino también, a la definición del rol del arquitecto y del urbanista en nuestra sociedad, se ha empleado una técnica de investigación social cualitativa: la entrevista semidirectiva. A partir de un cuestionario base compuesto por una decena de preguntas, se planteó a los entrevistados un viaje hacia el pasado, con el fin de escudriñar y extraer de su memoria elementos para la reflexión aquí propuesta.

Cada una de las entregas previstas a partir de este número presentará una triada de invitados, integrados de acuerdo con sus afinidades en cuanto a los campos y los temas profesionales en los cuales se han desempeñado. Se da inicio con tres arquitectos y urbanistas de origen y cultura diferentes, que realizaron sus estudios de pregrado en arquitectura durante los años sesenta, y setenta: el argentino Juan Carlos Pérgolis Valsecchi (Buenos Aires, 1943) y los colombianos René Carrasco Rey (Quibdó, 1942) y Juan Carlos del Castillo (Bogotá, 1952).

Se espera que, al sondear la memoria de los protagonistas de esta historia, aún por escribirse, el presente texto pueda estimular el interés de nuevas generaciones de estudiantes e investigadores en el estudio y el conocimiento de la historia de la enseñanza de las profesiones aquí evocadas.

6 En este punto, es importante precisar que la presente iniciativa por recoger esta serie de testimonios tiene como referencia directa un conjunto de trabajos y sus respectivos aspectos metodológicos, propuestos y aplicados dentro del marco de proyecto que desde 2015 se ha ocupado del caso francés: se trata del programa Histoire de l'Enseignement de l'Architecture au XXe siècle (HEnsA20), dirigido por Anne-Marie Châtelet, Marie-Jeanne Dumont y Daniel Le Couédic, y financiado por el Ministère de la Culture. https://www.culture.gouv. fr/Nous-connaitre/Decouvrir-le-ministere/Histoire-du-ministere/Evenements/Recherche/Pour-une-histoire-de-l-enseignement-de-I-architecture/Programme-de-recherche/ Panorama-de-I-histoire-de-I-enseignement-de-I-architecture-en-France 


\section{Conversaciones con Juan Carlos Pérgolis Valsecchi, René Carrasco Rey y Juan Carlos del Castillo}
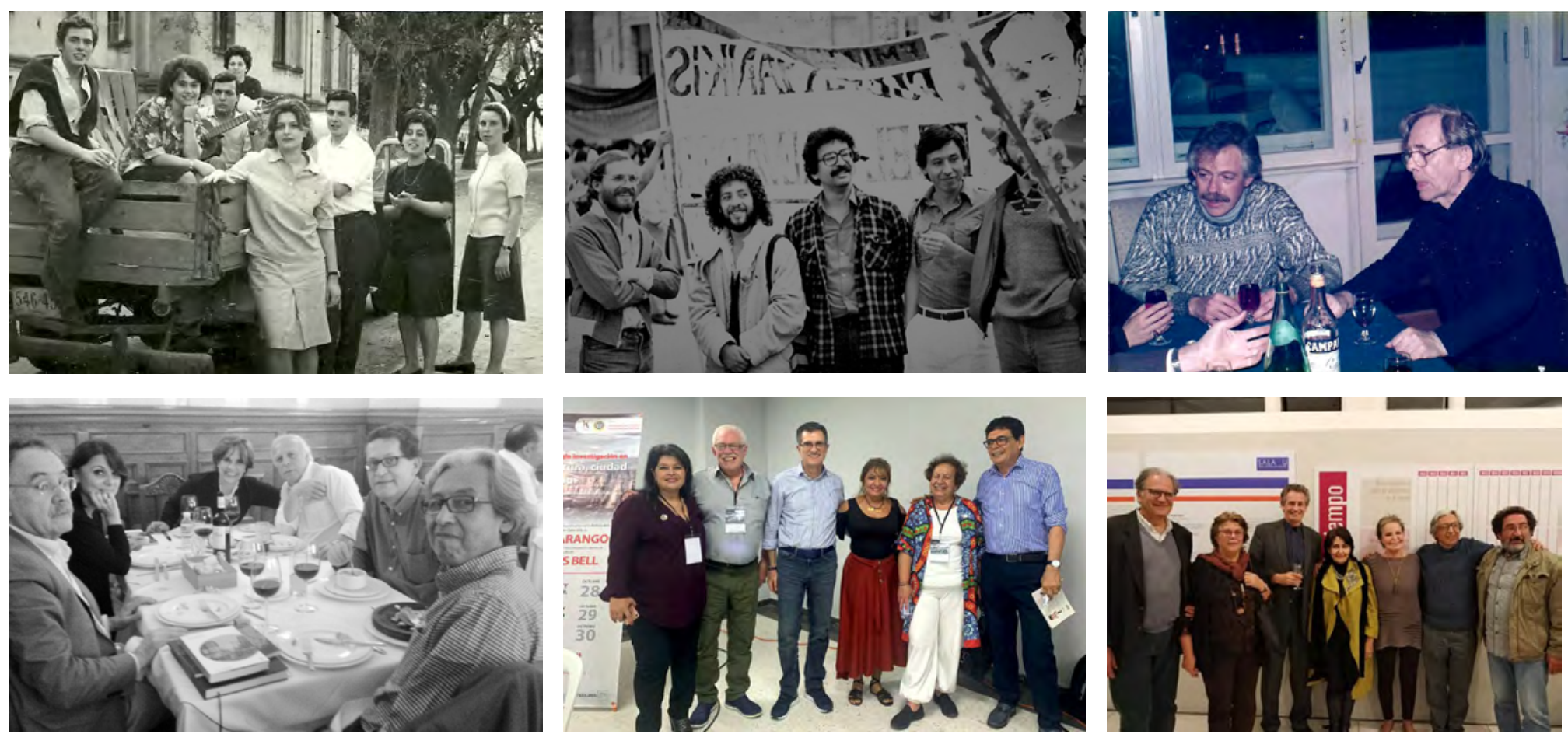

Andrés Ávila Gómez [AAG]: Antes de adentrarnos en el tema de su formación como arquitecto, ipodría contarnos sobre sus orígenes, y si, de alguna manera, su interés en la arquitectura tiene algún precedente en su familia? ¿Cómo cree usted que la cultura material (cómics, films y programas de televisión, música, etc.) con la cual tuvo contacto durante su infancia y su adolescencia pudo haber estimulado su interés en el arte, la arquitectura y la ciudad?

Juan Carlos Pérgolis Valsecchi [JCPV]: Me viene a la mente una frase de Orhan Pamuk (2007) en su obra Estambul: ciudad y recuerdos (Istanbul: Memories and the City): "Todo aquel que desea darle un significado a la vida se ha preguntado, al menos una vez, durante su existencia, por el sentido del lugar y el momento en que ha nacido". Esta sencilla frase de Pamuk me explicó muchos sucesos de mi vida y mi actitud hacia la historia y la teoría de la arquitectura y la ciudad. En otro momento del texto, Pamuk agrega:

Lo que a mí me ha determinado ha sido permanecer ligado a la misma casa, a la misma calle, al mismo paisaje, a la misma ciudad [...] el destino de la ciudad era el mío porque es ella quien ha formado mi carácter.

Esto lo puedo trasladar a mi propia vida, pues, aunque muy temprano me fui de La Plata — mi ciudad natal—, no puedo negar la influencia que tuvo en mí esa ciudad, con su trazado geométrico, su arquitectura neoclásica y sus grandes espacios verdes, De igual manera, no puedo ignorar la influencia del pensamiento de los años sesenta en mi formación. Pero el gran aporte fueron los colegios públicos del Estado, en aquellos años de la Argentina, de enseñanza amplia, libre e incluyente ofrecida entonces en mi país: yo estudié en la escuela pública № 2 de La Plata y luego en el Colegio Nacional de la Universidad Nacional de La Plata.

El trabajo en historia y teoría de la ciudad implica partir de los lugares y los acontecimientos que me rodearon, y es por ello inevitable partir de las huellas que llevo en el inconsciente. En mi formación, emergen siempre dos conceptos que quisiera mencionar: la idea de Zeitgeist, o espíritu del tiempo, ese corpus de objetos y actitudes culturales - entre ellas, la arquitectura y la ciudad- que deben ser observadas simultáneamente, sin excluir nada. El otro concepto es la idea de sujeto en proceso, elaborada por la filóloga Julia Kristeva (1978), ya que esa presencia de imágenes y vivencias en el inconsciente pone en evidencia que no podemos evitar ser parte activa en cualquier proceso que iniciemos, ya que, desde la primera aproximación al tema hasta las conclusiones, no lo hacemos desde la razón, sino desde el deseo.

René Carrasco Rey [RCR]: Pertenezco a la generación de los años cuarenta, 1942; nací en Quibdó, departamento del Chocó, me crie en Cartagena y Barranquilla y estudié en Cali, Bogotá y París. La pertenencia a un lugar geográfico o a una cultura local con la cual me identificara no fue una alternativa. Siguiendo un patrón clásico, en las familias colombianas siempre había un personaje que sobresalía o se distinguía en la comunidad, y que era referencia para que las descendencias siguieran el camino del progreso. En la mía, fue el primo Reinaldo Valencia Rey, que había llegado de Francia luego de 


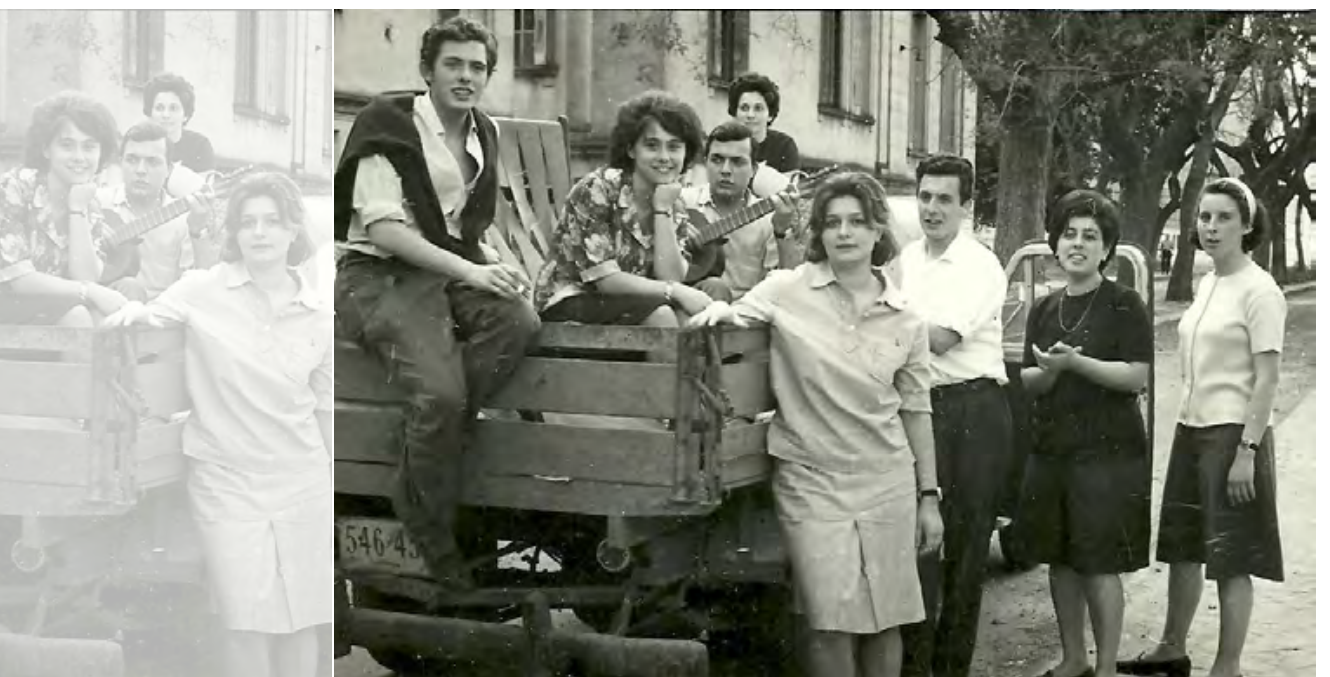

(4) Figura 1. En la nueva Facultad de Arquitectura, Universidad Nacional de La Plata. 1963

Fuente: Arq. Viviana Schaposnik/ Archivo personal J. C. Pérgolis

Nota: "Fue tomada el día en que Arquitectura dejó de ser un Depto. de ngeniería y se convirtió en Facultad. Nos estábamos mudando del Quonset (el viejo galpón de la II Guerra) donde funcionábamos, a un edificio. Yo estoy sentado a a izquierda, en el borde del platón del vehículo. En la foto hay amigos y compañeros muy queridos, algunos desaparecidos durante la dictadura militar de Argentina; tros emigraron a Europa (lugar de origen de nuestros padres o abuelos) por el mismo motivo. Con quienes quedaron en Argentina -en La Plata- sigo en contacto. Viviana Schaposnik, la de la foto, es la chica que está sentada junto a mi" propietaria de la camioneta y trabajar en París en el taller de Le Corbusier situado en la rue de Sèvres ${ }^{7}$, y se hizo conocido en este medio profesional por su propuesta urbana para Bogotá. En esta trama cultural, mi madre me insistió desde el bachillerato [en] que esa era la profesión más próxima a la condición innata que había manifestado desde pequeño por el dibujo como expresión de mis ideas; así, el arte pasó a ser parte de mi actividad cotidiana, pues ganaba los concursos para diseñar los mosaicos del colegio, hacía caricaturas de mis compañeros y paisajes de la ciudad. También me entusiasmaba mirar las casas modernas localizadas en una colina cercana a la estatua de Belalcázar, en la ciudad de Cali: me seducían sus planos blancos, las líneas horizontales y los vacíos oscuros que dejaban por las características del clima. Así sería mi casa, de la cual hice varios bocetos.

En tal contexto, mi destino estaba en la Facultad de Arquitectura de la Universidad Nacional, de Colombia (UN), junto con la élite de la arquitectura colombiana: Fernando Martínez Sanabria (1925-1991), Rogelio Salmona (19272007), Hernán Vieco Sánchez (1924-2012), Reinaldo Valencia Rey (1922-1994), de la "escuela" francesa; Dicken Castro (1922-2016) y Enrique Triana Uribe (1929-2009), de la "escuela" norteamericana; Guillermo Bermúdez Umaña (1924-1995) y Roberto Londoño Domínguez (1933-2011), de la Universidad Nacional; o los primeros urbanistas: Manuel García Camacho (1928-1999), Edgar Burbano Pérez (1922-1998) y Leonardo Ayala, de influencia europea.

Por otro lado, en los años cincuenta la televisión no tenía ningún interés para la juventud de la época, y lo único arquitectónico que encontré en los cómics fue una casa debajo de un puente, en Dick Tracy. Por el contrario, la literatura sí me aproximaba más a la idea del espacio urbano en diferentes escalas; el cosmos ficticio de Yoknapatawha, creado por William Faulkner, lo tuve en mi mente hasta la aparición de Macondo. Esa descripción de un espacio que se identificaba con una sociedad específica es todavía uno de los principios con los que comienzo mis clases. También tengo presente las imágenes detalladas de las sensuales habitaciones de Las mil y una noches, de la literatura árabe, y la descripción cuidadosa de los ambientes urbanos del Dublín de James Joyce en el Ulises (1922).

Juan Carlos del Castillo [JCDC]: Provengo de una familia de clase media, provinciana, conservadora y católica, a la que le fue removido el piso y sus cimientos culturales y sociales en esa segunda mitad del siglo. Mi padre, Carlos del Castillo Isaza, fue enviado a educarse desde adolescente a la Capital de la República. Y terminados sus estudios secundarios en el ya desaparecido Colegio Mayor de Nuestra Señora del Rosario (Quinta de Mutis), se inclinó por la arquitectura, no sé bajo qué influencia, pues mi abuelo fue un campesino acomodado, pero inculto. Mi padre inició su formación de arquitecto en la Universidad Nacional de Colombia y la terminó en Columbia University, en New York; sin embargo, ejerció muy poco su profesión, pues de vuelta al país se dedicó de lleno a la actividad política, como miembro del Congreso de la República de Colombia por espacio de tres décadas. Por esta razón, en mi infancia oí hablar algo de arquitectura y de arte, pero, sobre todo, de política; sin embargo, mi padre había cultivado ciertos "gustos de arquitecto". Adquirió parte de la obra pictórica de uno de sus compañeros de estudios, reconocido después como un artista destacado en la plástica colombiana de los años sesenta y setenta, Eduardo Ramírez Villamizar (1922-2004). La biblioteca familiar, el mobiliario doméstico y la discografía también registraron alguna huella de una estética distinta de la iconografía religiosa y de la zarzuela y el cuplé español. El paso por New York, sin duda, lo acercó más a otro referente cultural.

La radio, las revistas, la música y los posters fueron, en mi caso, los principales vínculos que tuve en mi infancia con el nuevo mundo urbano y cultural que presenciamos en la década de los sesenta. A mi casa en el barrio El Campín llegaba la revista Life; que fue para mí, una potente ventana con el "mundo externo". También oíamos la emisora cultural más caracterizada de la época: la H.J.C. $\mathrm{K}^{8}$, y al sintonizarla todos los domingos estábamos pendientes de dos programas radiales: Monitor en la mañana y Teatro del mundo en la noche. Esta radiodifusión dominical fue un gran estímulo y reflector para introducirme en otro imaginario: el de un mundo desconocido y fascinante, y el mejor recuerdo que tengo de los días de infancia. Monitor era una revista personalidades entre quienes estaban Eduardo Caballero Calderón, Álvaro Castaño Castillo. Bajo el célebre eslogan: "El mundo en Bogotá", esta emisora de programación cultural transmitió en FM desde 1967 hasta 2005. 
sonora con las voces de ingeniosos corresponsales en New York, París, Roma, Moscú y Madrid que gracias a sus relatos nos hacían sentir paseando por sus calles, sus cafés y sus espectáculos. Recuerdo vivamente las voces de Luis Gaitán y su esposa Doris Castañeda, desde París, y a Pedro Clavijo, desde Moscú. Teatro del mundo fue una gran experiencia del género sonoro del radio-teatro que nos introdujo al mágico escenario de los mundos simbólicos. La revista Life, cuyo eslogan era "To see Life, see the world", y su énfasis en el formato de fotoperiodismo me mostró gráficamente dos terremotos sociales y culturales de los años sesenta que tuvieron gran influencia en mi adolescencia y en mi vida: los movimientos estudiantiles y sociales de 1968 (movimiento por los derechos civiles y contra la guerra en Vietnam, en Estados Unidos; el Mayo del 68, en París; la matanza de Tlatelolco, en Ciudad de México; la Primavera de Praga...), y el gran movimiento de la contracultura de los jóvenes en Estados Unidos y Europa. Y esto me llevó a los posters. La gran revolución gráfica e iconográfica que acompañó estos dos acontecimientos me impactó de forma contundente. Mis primeras incursiones en la gráfica y de empatía con el pop art las hice a través del diseño de posters centrados en la imagen de la calle y de los jóvenes felices, desarreglados, descomplicados, rebeldes, de pelo largo y amorosos. Y la atmósfera y el espíritu de las contraculturas me introducen, también de manera muy potente, al mundo de la música y de sus nuevas formas delirantes en su creación y difusión, eminentemente urbanas, callejeras. Quizá, de ahí proviene mi gusto inicial por la ciudad y sus expresiones culturales.

[AAG]: ¿Qué lo llevó a escoger finalmente un determinado programa, y la institución a la cual ingresó? ¿Cómo influyó eso durante su paso por las aulas universitarias, el contexto sociocultural de la época y, en general, la situación de su país?

[JCPV]: Ingresé en 1961, cuando todavía era un departamento de la Facultad de Ingeniería, que después se convirtió en Facultad de Arquitectura y Urbanismo de la Universidad Nacional de La Plata (UNLP) (figura 1). En aquellos años era una facultad pequeña, de gente de provincia, una especie de comunidad ideal de profesores y estudiantes, hasta el golpe de Estado de 1966, cuando sobrevino una de las tantas dictaduras militares de Argentina - y esta vez, tal vez, una de las más burdas y retrógradas-

[RCR]: Realmente, por decisión de mi padre, yo iba a estudiar en la Pontificia Universidad Javeriana de Cali — que es una institución privada-, puesto que mi bachillerato lo hice en esta ciudad, en un colegio de la Compañía de Jesús, con los jesuitas, y todos mis amigos seguían la ruta del establecimiento; sin embargo, mi primo, el arquitecto Reinaldo Valencia Rey, me planteó la siguiente disyuntiva: "¿Usted quiere aprender arquitectura o construir edificios?".
Entré entonces a la universidad pública, y mi contacto con los compañeros del colegio evidenciaba una especie de confrontación: teníamos miradas diferentes sobre el contexto sociocultural de la época. En mi caso, estaba en un medio que apoyaba a los movimientos estudiantiles anticulturales, cuestionaba abiertamente a la burguesía dominante y potenciaba la discusión en torno a otros asuntos que hacían parte del debate en las universidades públicas. En resumen, mi experiencia universitaria me trajo nuevos amigos y me acercó a la literatura, al cine y al arte de vanguardia.

Nuestro mundo se concentraba en el centro de Bogotá: en la librería Buchholz siempre abierta del señor Karl Buchholz ${ }^{9}$ (1901-1992) -donde desaparecían los libros sin que nadie se diera cuenta-, en las galerías de arte del señor Casimiro Eiger Silberstein ${ }^{10}$ (1909-1987), pero también, en los cafés y las discotecas que recorríamos semanalmente. El Cisne era el lugar de encuentro para arquitectos, escritores y pintores - a la manera del célebre Café de Flore, ubicado en el barrio parisino de Saint-Germain-desPrés-: allí, detrás de bastidores, escuchábamos atentamente sus deliberaciones sobre el transcurrir del pensamiento moderno, cuando ya se ponía en duda la estabilidad de la modernidad, al final de los años sesenta. A las 10:00 p. m. lo cerraban, y nosotros, en fila, los seguíamos hasta

9 Nacido en Göttingen, Alemania, Buchholz había fundado su primera librería en Berlín, cuando apenas tenía 24 años; y más tarde abrió otras en Madrid, Lisboa, y Bucarest. En 1949 se instaló definitivamente en Colombia. Ver la entrevista concedida a Luz Angela Fandiño para el diario El Siglo. https:// esquinatomada.com/textos/karl-buchholz-una-vida-entre-libro/. Ver también

10 Nacido en Varsovia, Polonia, Eiger estudió derecho en la Université de Genève, y más tarde hizo estudios en historia del arte en la Sorbonne de París, pero tuvo que abandonar Francia tras el inicio de la Segunda Guerra. Tras un accidentado periplo buscando un país en donde establecerse, se instaló en Bogotá en 1943, y ya en 1946 fue nombrado jefe de los servicios culturales de la Embajada de Francia en Colombia. Entre 1951 y 1961 dirigió la Galería El Callejón, y posteriormente la Galería de Arte Moderno. https://enciclopedia.banrepcultural.org/index.php/Casimiro_Eiger.
(1) Figura 2. Participando activamente en una manifestación en la plaza de Bolívar, en 1973.

Fuente: Archivo personal J. C. del Castillo

Nota: De izquierda a derecha: Gonzalo Jiménez, Guarín, Luis Fernando Maldonado, Juan Carlos del Castillo y Jesús Duarte.

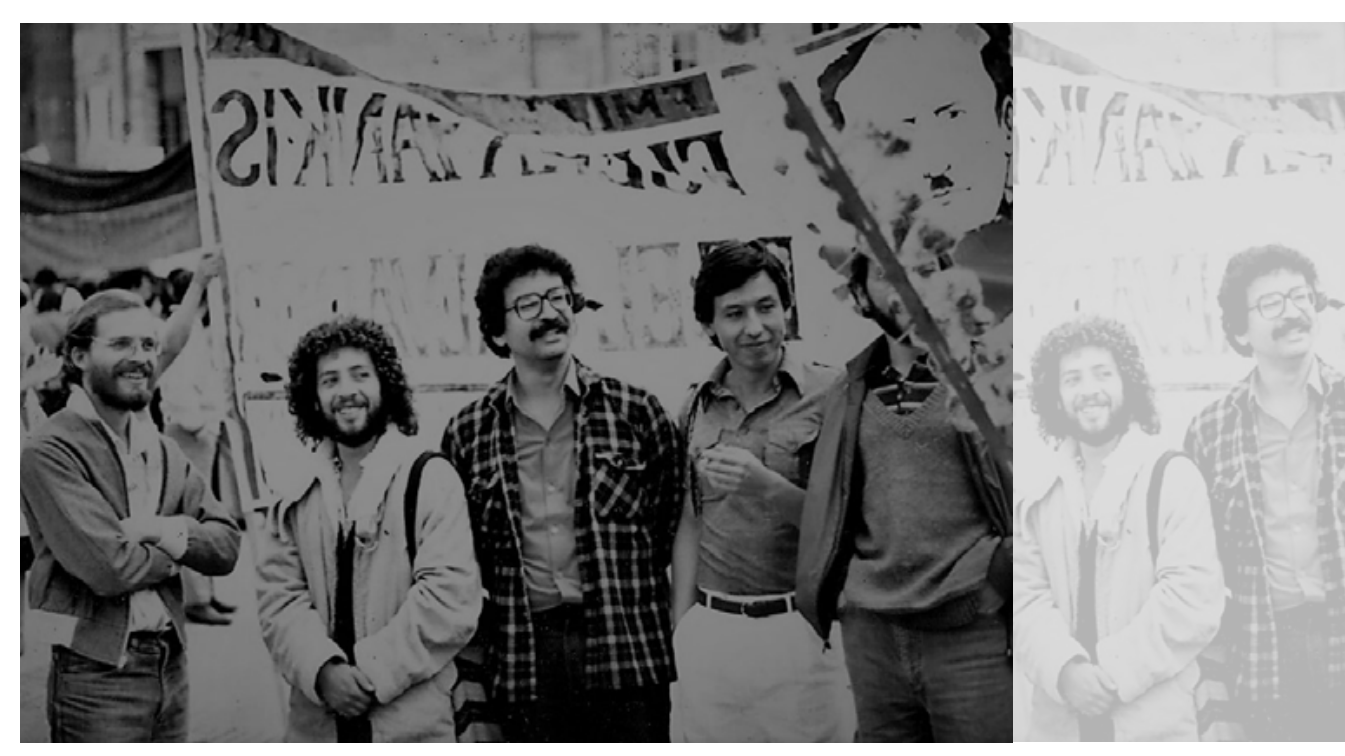


La Pampa, el bar de Plinio y Peggy, a oír jazz, o al sótano de La Quintrala, para bailar.

Había pasado de lecturas como El lobo estepario (Der Steppenwolf, 1927), de Herman Hesse, en el bachillerato, al existencialismo de Jean-Paul Sartre; con suéter negro de cuello alto, estudiando los proyectos publicados en la revista francesa L'Architecture d'Aujourd'Hui, donde se reforzaba el discurso del movimiento moderno como una verdad universal, soportado, con muy pocas excepciones, por la mayoría de los profesores.

[JCDC]: Hice mi secundaria en el mismo colegio en el que estudió mi padre y fui a la misma universidad donde inició su formación como arquitecto; además, mi memoria infantil guardaba un recuerdo muy grato del campus de la Universidad Nacional, porque era el lugar al que mi padre me llevaba de paseo con cierta frecuencia. Siempre he tenido la imagen viva y grata de la verde y frondosa vegetación, del espacio amplio, limpio y silencioso y de la enorme jaula donde anidaba una pareja de cóndores andinos. Por último, y lo más importante, porque la Universidad Nacional era, y sigue siendo, el centro de educación superior de mayor calidad del país.

Sobre la elección del programa, creo que [en] lo que me aproximó a escoger ese programa tuvo que ver el referente, que he señalado, de la profesión de mi padre, porque siempre habría preferido su imagen como arquitecto, más que como político. Por otra parte, en el espectro disciplinar, mi empatía era clara con el campo de las artes; quizá, por el hecho de que había desarrollado cierta familiaridad con el arte a través de la pintura de posters, y por mi fascinación con las expresiones culturales urbanas. Jamás me vi como abogado, ni como médico ni como agrónomo. Por eso, a los 17 años, y llegado el momento de tomar la decisión sobre mi formación profesional, tuve una idea fija: estudiar arquitectura, y en la Universidad Nacional de Colombia. Me presenté al examen de admisión con la absoluta certeza de que ingresaría. No hice el intento en ninguna otra universidad, ni consideré otra disciplina. Creo que fue una decisión muy sensorial y emocional; quizá, también, una decisión cómoda.

La influencia del contexto sociocultural de la ciudad en mis días de aulas y en mi vida estudiantil es muy claro. El primer encuentro con la escuela y sus métodos pedagógicos no fue muy atractivo. Pero el encuentro con la vorágine de la época si fue un encanto. Fue un encuentro fascinante con una forma de vivir y de sentir, con un movimiento social de jóvenes en efervescencia y una ciudad y un país que estaban siendo sometidos a un estremecimiento y una convulsión sin precedentes (figura 2).

La universidad fue el instrumento y el método para romper el cascarón de ese entorno familiar, social y de vida, marcado por la visión conservadora, católica, estrecha, provinciana, desluci- da y anodina. Nos volvimos entonces seguidores de las banderas libertarias de los sin religión, sin patria, sin ataduras ni cadenas, sin propiedad, sin prohibiciones; y por eso nos hicimos ateos, agnósticos, marxistas, pacifistas, fiesteros, seguidores del amor libre, del libre desarrollo de la personalidad y, por tanto, del libre consumo de alcohol, tabaco o marihuana.

[AAG]: Durante sus años de formación académica, ¿cuáles eran las lecturas (de historia y de teoría de la arquitectura, de disciplinas en ciencias sociales y humanas o de literatura en general) en boga en aquellos años entre los estudiantes de arquitectura y de artes de su entorno?

¿Existían tendencias identificables? Y si así era, ¿con cuáles de ellas llegó a identificarse o a enfrentarse, y por qué?

¿Existían espacios fuera de la vida universitaria (círculos de lectura, cineclubes, etc.) en los cuales haya desarrollado su curiosidad intelectual?

¿Cuáles eran las principales influencias (autores, libros, metodologías, etc.) que llegaban por entonces de otros medios académicos y profesionales europeos, norteamericanos, latinoamericanos $u$ otros?

[JCPV]: Las dicotomías son muy comunes y fuertes en Argentina, en campos como la política o el fútbol. En nuestra facultad de arquitectura, esto se expresaba en polaridades como las suscitadas entre racionalistas-corbusieranos y organicistas-wrightianos; y como suele suceder en política o en fútbol, no había espacio para una tercera fuerza. Las cosas empezaron a cambiar a finales de los años sesenta, con la difusión de textos de Reyner Banham, Alison y Peter Smithson, James Stirling y, por supuesto, Archigram: lo que llegaba de Inglaterra tuvo un gran peso en nuestra formación. Tal vez allí, a través de los textos de Thomas Gordon Cullen, comenzamos a entender la ciudad. Curiosamente, Jane Jacobs no estaba en nuestro horizonte, ya que la ciudad que ella señalaba como perdida, que correspondía a lo que ella añoraba en su entorno norteamericano, era la que aun entonces afortunadamente - nos rodeaba en La Plata. Más tarde, durante mi actividad en la Colombia de los años ochenta, rossianos, posmodernos y krierianos estuvieron presentes en mi vida académica, alimentando, especialmente mi trabajo como escritor en la revista Escala. Y debo confesarlo: aún hoy me emociona el discurso urbano de Aldo Rossi, e incluso, el de los hermanos León y Rob Krier, aunque me sigue doliendo el paso del Charles Jencks más analítico y crítico de Modern Movements in Architecture (1973) al "Jencks light" de años posteriores.

[RCR]: Partamos del hecho de que todos éramos, igual que nuestros profesores, seguidores incondicionales del movimiento moderno. Éramos como una secta de seguidores del Congreso Internacional de Arquitectura Moderna (CIAM); 
Ávila-Gómez, A. (202I). Reflexiones en torno a la enseñanza de la arquitectura y el urbanismo en Colombia: Conversaciones con Juan Carlos Pérgolis Valsecchi, René Carrasco Rey y Juan Carlos Del Castillo. Revista de Arquitectura (Bogotá), 23(I), 3-19. https://doi.org/I0.147/8/ RevArq.2021.3850

no había espacio para otras tendencias, nadie discutía los principios del movimiento. De pronto, en los últimos años, escuchamos hablar de Alvar Aalto o de Frank Lloyd Wright, pero considerados como unos personajes con una ideas raras y simpáticas que nunca valoramos realmente.

Nuestros libros eran el Álgebra de Aurelio Baldor, la geometría descriptiva, el libro para cálculo integral y las matemáticas de algún autor. Por fuera de la escuela, los espacios del entretenimiento eran los cineclubes, los conciertos en la recién inaugurada sala de música de la Biblioteca Luis Ángel Arango o los teatros de cine; especialmente, para ver unas diez veces 2001: Odisea del espacio, de Stanley Kubrick (2001: A Space Odyssey, 1968), en condiciones de alta sensibilidad. La novela francesa y los estudios sobre el estructuralismo estaban en mi biblioteca, hasta la llegada de Cien años de soledad (1967) y de las obras del boom de escritores latinoamericanos, cuyos temas acaparaban las conversaciones del almuerzo y de las fiestas.

[JCDC]: Por el contexto que he descrito, es fácil comprender que en la universidad pública brotó con mucha fuerza el debate político y cultural sobre una nación en transición; en nuestra escuela, ese debate se orientó sobre el papel de la arquitectura, el urbanismo y el arte frente a esa nueva realidad. Así, la crítica a lo que se venía haciendo y enseñando se convirtió en el epicentro de la reflexión, las lecturas y las conversaciones.

Dos tradiciones culturales podrían reconocerse como influyentes en el inicio de la década de los setenta en la Facultad de Artes. En el campo de los docentes, algunos tenían cierta información de la crítica al movimiento moderno, proveniente de la tradición anglosajona, en autores como Christopher Alexander, y su trabajo A City is not a Tree (1965), y Robert Venturi, con Complexity and Contradiction in Architecture (1966). Por otra parte, la crítica proveniente de la tradición francesa y los autores y la literatura marxistas encontraron un campo propicio dentro de los estudiantes y los pocos docentes que se habían formado en Francia. Henri Lefebvre y sus dos trabajos Le droit à la ville (1968) y La révolution urbaine (1970) tuvieron notable influencia en quienes empezábamos a interesarnos en el tema de la ciudad y el urbanismo; y por otra parte, Françoise Choay, y su texto L'Urbanisme: utopies et réalités (1965). La revisión crítica al Movimiento Moderno y el Congreso Internacional de Arquitectura (CIAM) que empezó a conocerse y a circular tuvo dos fuentes principales. Por un lado, el aporte de "La Tendenza", a esa crítica, con autores como Rossi y Aymonino; y por otro, el trabajo de Jane Jacobs. Estos fueron los autores que empezaron a ser leídos.

Quizá, los docentes del área de Historia del Arte y de la Arquitectura fueron más sistemáticos en el manejo bibliográfico. De ellos, conocimos autores como Nikolaus Pevsner, Leonardo Benevolo, Jacob Burckhardt, Erwin Panovsky, Pierre Francastel y Giulio Carlo Argan.

La otra fuente bibliográfica que consultábamos los estudiantes era la proporcionada por las revistas. Las que se producían en el país fueron las revistas Proa y Escala. Otras disponibles en bibliotecas fueron Arquitectura, Cuadernos de Arquitectura y L'Architecture d'aujourd'hui.

[AAG]: Siempre existen asignaturas y maestros que marcan profundamente nuestro paso por las aulas: ¿Cuáles fueron aquellas materias y profesores que despertaron o avivaron su gusto por la arquitectura o el urbanismo?

¿Tuvo durante aquellos años algún reparo contra el modelo pedagógico vigente; en especial, en lo que respecta a la enseñanza en el Taller de Arquitectura?

[JCPV]: Hasta el golpe militar de 1966, la facultad funcionó con talleres verticales, y hasta ese año, justamente, estuve en el taller del arquitecto Jorge Chute. Juntos pasamos del racionalismo a ultranza al disfrute de las novedades que llegaban de Inglaterra; sobre todo, al discurso también racionalista de Stirling. Jorge Chute nos enseñó a sentir la arquitectura: nos hablaba de la fluencia o la plasticidad del espacio; analizábamos los edificios centralizados de Constantinopla o "el juego de la luz sobre los volúmenes" en Le Corbusier; relacionábamos sonidos y formas, ritmos y secuencias; escuchábamos las canciones de la cantante sudafricana Miriam Makeba o a los barrocos. En fin, el taller vertical parecía reunir todo el conocimiento, y aunque las materias no perdían su independencia, en el taller se generaba todo tipo de relaciones entre los conocimientos.

En el cine, fueron para nosotros los años de la Nouvelle Vague —inolvidable el Orfeu Negro (1959) de Marcel Camus-; del Ingmar Bergman más oscuro - El mago (1958) y El manantial de la doncella (1960)_; de las maravillas alucinantes de Federico Fellini, y de una fantástica película de Alain Resnais que mostraba el juego entre realidad e ilusión en un mundo de formas barrocas: L'année derniere à Marienbad (1961) (El año pasado en Marienbad). Incluso, atraído profundamente por esta película, viajé más tarde a Praga, para luego pasar por Marienbad (hoy, Marianske Lazne), un pequeño balneario cercano a Karlovy Vary, el gran lugar barroco de baños en la Republica Checa; y sin embargo, descubrí que no existían allí las locaciones de la película.

Volviendo al tema de los profesores que inspiraban por su forma de enseñar, Julio Ángel Morosi (1926-2006), quien nos impartió durante dos años la cátedra de Urbanismo, merece un párrafo especial. Diplomado como Arquitecto, Ingeniero Civil, e Ingeniero Hidráulico en la Universidad de La Plata, Morosi realizo estudios de posgrado en Suecia, donde vivió casi treinta 
años, nos ilustraba permanentemente acerca de los barrios modernos de ciudades escandinavas, como Vâllingby, cerca de Estocolmo; Farum, cerca de Copehague, y tantos otros.

Mi primer trabajo docente fue en su cátedra, como ayudante alumno —algo así como un monitor-, y más allá de sus conocimientos, fue la amplitud de su mirada a la ciudad y al mundo que lo rodeaba lo que acabó de convencerme: mi objeto de trabajo sería la ciudad.

[RCR]: Hablamos de una escuela de arquitectura con un pensamiento en torno a las ideas del movimiento moderno. La figura dominante, por su temperamento y su trayectoria profesional, era Fernando Martínez Sanabria, quien tenía una amplia cultura y conocimiento sobre las artes, la literatura y la música. Él marcaba los lineamientos de la escuela a través de las tesis de grado, a cuyas presentaciones asistían invitados externos, quienes, en presencia de los estudiantes de la escuela, ya debatían y cuestionaban el racionalismo y la ausencia de significados de los proyectos modernos.

En cuanto a las materias, yo asistía a las clases de dibujo a mano alzada e historia de la arquitectura, que me generaban una enorme emoción y a las cuales les dedicaba mucho tiempo, pero el Taller de Diseño era la vida. La escuela ofrecía un curso de urbanismo opcional, propuesto por el Departamento de Urbanismo, y que consistía en levantar barrios de la ciudad; pero en ese momento no fue un tema de mi interés.

Lo cierto es que [por] entonces la reestructuración universitaria hacía parte del movimiento por el desarrollo económico que rondaba por toda América Latina, promovido por la Comisión Económica para América Latina y el Caribe (CEPAL) y Estados Unidos, con el fin de realizar reformas institucionales para "ahondar" en el proceso de industrialización. La apuesta de las universidades estaba en la transformación de la sociedad, como instrumento para la erradicación del subdesarrollo, y para ello era necesario preparar profesionales que respondieran a las necesidades del país. Se iniciaron así críticas al modelo educativo tradicional, dedicado a la enseñanza del oficio sin relacionarlo con la cultura o los temas nacionales. De ahí partió la propuesta de integrar las antiguas facultades disciplinares en grandes facultades, donde aquellas se convirtieron en departamentos o escuelas, con el objetivo de ampliar y diversificar la enseñanza. Como estrategia, se propusieron dos niveles en la modificación del pénsum: los estudios generales y los estudios básicos.

La Facultad de Arquitectura que existía se transformó en un departamento de la Facultad de Artes, con la oposición de algunos profesores y estudiantes, y la aprobación de otros, entre los cuales me incluía. Con este cambio se retomó la experiencia de la Bauhaus, claramente expuesta por Alberto Saldarriaga Roa en su clase de Histo- ria de la Arquitectura, buscando una integración con la pintura, la escultura, el teatro y el cine.

La incorporación de los idiomas y las humanidades como componentes de los estudios generales en arquitectura fue determinante. Siguiendo los pasos de mi primo arquitecto, Reinaldo Valencia Rey, el francés era ya mi segundo idioma, pero las humanidades con el profesor Howard Rochester (1905-1998), un jamaiquino con presencia de lord inglés, educado en el St. Georges College de Cambridge, condecorado por la reina Isabel, me abrió el universo hacia otras áreas del conocimiento hasta entonces cerradas por el rigor de los componentes del oficio de la arquitectura. Dentro del marco de esta reforma, pude asistir a cursos de antropología, con Virginia Gutiérrez de Pineda (1921-1999), y de filosofía, con Chantal Mouffe, o a las conferencias de Orlando Fals Borda (1925-2008) en el Departamento de Sociología. Para ese momento el Museo de Arte Moderno, bajo la dirección de Marta Traba (1930-1983), tenía su sede en la Universidad Nacional; asistíamos a las exposiciones y a conciertos de jazz los viernes por la tarde; al Galileo Galilei, de Bertolt Brecht, dirigido por Santiago García (1928-2020)... todo un mundo de sistemas culturales que se entrelazaban con los códigos del diseño arquitectónico que, a mi parecer, daban soporte a los argumentos de mis proyectos, como lo pude demostrar en mi trabajo de tesis.

[JCDC]: El currículo en la escuela de arquitectura y los métodos de enseñanza eran un asunto muy difícil de captar y de entender, en mi opinión, por tres razones fundamentales: era muy fragmentado, era muy dependiente de los gustos y preferencias de los docentes y [contaba] con muy poco apoyo en metodologías pedagógicas probadas; sin embargo, durante mi paso por las aulas tuve interés en asignaturas relacionadas con la historia de la ciudad, la sociología urbana y el urbanismo. El Taller de Diseño y el área de las asignaturas técnicas no fueron un referente potente para mi formación.

En el área del Taller de Diseño, en realidad solo recuerdo y tengo reconocimiento por dos profesores: en primer semestre, por el director del taller: el arquitecto más veterano, Dicken Castro, por su sensibilidad para captar y orientar ideas muy primitivas, confusas y en borrador de alumnos que hacían su primera experiencia en ejercicios de diseño. $Y$ en el séptimo semestre, por el arquitecto Enrique Triana Uribe, con gran experiencia en el oficio y una excelente capacidad y sentido del humor como método pedagógico.

Tres docentes formados en la corriente de la sociología urbana y el urbanismo francés, impactados por el mayo del 68, y claramente marxistas, tuvieron notable influencia en mi orientación y mi preferencia por el tema de la ciudad y el urbanismo. La socióloga Ángela Inés Guzmán 
Calle (1935-2015) —quizá, la primera representante de su género en el urbanismo colombiano-, el arquitecto Emilio Pradilla Cobos y la economista Peralt Charum; los tres, llegados casi simultáneamente al país, procedentes de París y nuevos docentes del Departamento de Urbanismo.

Respecto a su pregunta sobre si hubo algún reparo o crítica al modelo pedagógico aplicado en las escuelas de arquitectura y artes, debo responder que sí, y muy fuerte. En 1973, un movimiento estudiantil de gran amplitud se propuso la reforma académica de los programas de la facultad, lo que culminó con un experimento inédito y único en la Universidad Nacional. Se pusieron en cuestión los currículos y el sistema pedagógico de todos los programas de pregrado que se dictaban en la Facultad de Artes. Se suspendieron las clases, se invitó a los docentes a tomarse un receso en sus despachos privados y todos los estudiantes nos metimos de lleno al proceso de revisión y crítica de los currículos y a formular una reforma. Esta actividad se tomó un semestre completo y terminó con un documento en el que se propuso un nuevo tipo de pénsum académico para cada carrera.

La crítica se centró en tres temas principales: 1) la arquitectura y las artes que se pretendía enseñar estaban totalmente desligadas de las necesidades y las expectativas de la sociedad y de la nación que estaba aflorando; 2) la enseñanza respondía a un enfoque reducido a la formación de profesionales medios para el mercado y para funciones subordinadas, y 3) esa formación estaba limitada a una simple trasmisión de información desactualizada, inconexa, sin una estructura coherente y carente de propósitos para la formación de profesionales críticos y capacitados para la investigación, la creación y la transformación de las realidades propias de nuestro contexto.

Aunque hubo un recibo obligado y a regañadientes del resultado de este trabajo, las directivas de la universidad y la facultad finalmente no aceptaron la propuesta de reforma, argumentando, sustancialmente, que el método que se había empleado era inadmisible.

[AAG]: Por favor, cuéntenos sobre su proyecto de tesis: ¿cómo seleccionó el tema? ¿Quién fue su director, y cómo ve usted hoy en día aqueIla última experiencia académica que le permitió obtener el diploma profesional?

¿Realizó algún tipo de "práctica profesional" antes de graduarse? Y si así fue, ¿podría contarnos sobre dicha experiencia?

[JCPV]: En aquella época no había proyecto de grado o tesis como lo conocemos hoy. En 1968, mi último proyecto de taller fue sobre vivienda, con una fuerte influencia de la obra del arquitecto de origen israelí Moshe Safdie en Canadá. Ya no existía el taller vertical, sino un apático y mediocre taller horizontal que había traído la dictadura militar del 66, y quizás yo veía el proyecto de Safdie como una herencia de los proyectos de Alison y Peter Smithson y de los brutalistas de principios de los años sesenta, mezclado con las imágenes tecnológicas de Archigram. Todos esos ingredientes me trasladaban a las añoradas charlas del desaparecido taller vertical.

Todos intentábamos graduarnos con la materia que más nos gustaba: para mí, esa materia fue Historia, y el tema escogido fue el simbolismo entre el Art Nouveau y el Pop Art explorando una pretendida comparación entre la euforia de finales del siglo XIX y el entusiasmo con que se vivían entonces los años sesenta. Esta era la época de Roy Lichtenstein, George Segal, Andy Warhol y el Instituto di Tella, en Buenos Aires; pero también, de The Beatles y la cultura pop. Años que anunciaban la politización de la siguiente década, que culminarían con la más feroz dictadura argentina: la de los militares de 1976.

Con el examen de Historia III, que trataba sobre el siglo XX, y que fue, de alguna manera, mi despedida de la facultad, comencé a investigar sobre semiótica, con los escritos de Oscar Masotta, y de la semiótica cultural urbana. Presenté el examen final en diciembre de 1969, y en enero de 1970 recogí el título en la ventanilla de Secretaría de la facultad.

Tampoco existía entonces la práctica profesional en la Facultad de Arquitectura, pero desde el primer año de la carrera tuve la oportunidad de trabajar en la sala de proyectos de arquitectura del Ministerio de Obras Públicas; primero, como dibujante, y más tarde, como proyectista. Allí hice mis primeros proyectos: una pequeña terminal de ómnibus en Adolfo Gonzales Chaves un pueblo de la provincia de Buenos Aires y un edificio para oficinas públicas en la ciudad de Necochea ciudad costera, puerto y centro turístico. Asombrosamente, los dos todavía existen, y en muy buen estado.

[RCR]: Mi profesor de tesis fue Fernando Martínez Sanabria, y fue él quien me planteó el tema de tesis. Le habían encargado el diseño de la fábrica de Bavaria en la periferia de Bogotá, de manera que este era un ejercicio informativo para él y una primera salida del esquema moderno para mí, pues la idea de un elemento simbólico que identificara la fábrica en su entorno rompía con la homogeneidad moderna. El proyecto fue publicado en la revista $A U N$ de la UN, y posteriormente expuesto en el Bouwcentrum de Rotterdam -institución del gobierno de los Países Bajos- y publicado en la revista $A U N$. Durante mi carrera no trabajé en ninguna oficina de arquitectos: me dediqué exclusivamente al estudio, lo cual alternaba con la fiesta.

[JCDC]: Por las consideraciones que he expuesto y por el hecho de que tuve un papel destacado en la dirección de ese proceso y ese movimiento, llegué a la convicción, con otros 
compañeros, de que la consecuencia elemental que esa crítica implicaba era asumir otro tipo de trabajo de grado. Por esa razón, me negué a hacer un proyecto de tesis tradicional, lo cual significaba que no quería ni debía hacer un proyecto de diseño arquitectónico como tesis de grado.

En reemplazo del curso Taller de Diseño XI, un grupo de cuatro estudiantes pedimos que se nos aceptara hacer una tesis bajo la modalidad de un "taller de investigación". Esto, naturalmente, constituyó un reto sin precedentes para las directivas de la facultad. Y después de un intenso forcejeo en el Consejo de Facultad, obtuvimos la autorización para incursionar en una "tesis teórica", en vez de realizar un proyecto arquitectónico. La tesis pretendía examinar relaciones y contradicciones existentes entre la arquitectura colombiana en ejercicio, la sociedad y la ciudad que necesitaba esa práctica y ese conocimiento, y el problema de su enseñanza. Por esa razón, la "tesis teórica" que propusimos se denominó Arquitectura, escuela y sociedad. El docente que aceptó el reto de dirigir esta "contratesis" fue el arquitecto Carlos Jiménez, un intelectual marxista, miembro y dirigente de un movimiento político en formación en el espectro de la izquierda colombiana, denominado Tendencia Socialista, movimiento que se distanciaba de la tradición del estalinismo internacional, de las corrientes maoístas y de los movimientos guerrilleros colombianos. Sobra decir que yo compartía ese enfoque.

La tesis tenía la pretensión de argumentar que la arquitectura y el urbanismo que se estaban haciendo y enseñando en Colombia estaban muy influenciados y sesgados por la visión y los requerimientos de la industria de la construcción, del negocio inmobiliario y de la actividad urbanizadora; todas, en pleno florecimiento y auge en la década de los setenta en el país, y cabalgando sobre el potente proceso de urbanización acelerada que estábamos presenciando. Se quería estudiar ese sesgo, porque al lado del florecimiento de las actividades señaladas y del mercado en ascenso estaba creciendo desaforadamente, también, la "ciudad informal", los asentamientos espontáneos y la urbanización "pirata", temas y realidades que ameritaban la atención de arquitectos, urbanistas y artistas; sobre todo, de los que formaba la universidad pública. Por propuesta y sugerencia del director de tesis, nos acercamos y nos apoyamos en la teoría gramsciana sobre la formación y el papel de los intelectuales orgánicos del poder y de las clases sociales y de la función de la escuela. Tengo que decir, con toda claridad y certeza, que esa tesis de grado fue una experiencia definitiva y contundente en mi formación y en mi acercamiento a la temática de la ciudad y el urbanismo, pero también me condujo de manera precisa al interés en la problemática de la ciudad latinoamericana contemporánea.
Finalmente, respecto a mis primeras experiencias laborales, es fácil comprender el por qué mis convicciones personales chocaban indefectiblemente con los requerimientos del tipo de profesional apetecido por el mercado. Por esa razón, tuve claro que mis posibilidades de trabajo estaban muy circunscritas al sector público, pero, además, donde no se tuviera noticia o información de mi perfil. Mi primer trabajo, antes de recibir mi título de arquitecto, fue como jefe de la oficina de planeación urbana, o de los servicios de urbanismo, en Chiquinquirá (departamento de Boyacá), una población intermedia, de la cual procede mi familia paterna, porque para sus autoridades prevalecía el imaginario de que "el hijo del político no podía ser ni comunista, ni ateo, aunque alguien lo sospechara".

[AAG]: En esta primera etapa formativa, ¿qué importancia tuvieron para usted los viajes de estudios? Y luego, de manera global, ¿podría contarnos cuáles fueron aquellos viajes que marcaron su formación profesional e intelectual, y en qué contexto se dieron (institucionales o personales)?

La mayor parte de su vida está ligada a Colombia. ¿Cuándo y por qué decide instalarse en la capital colombiana?

[JCPV]: Gracias a un curso institucional sobre geografía humana, con el célebre geógrafo francés Pierre George, organizado por el Ministerio de Obras Públicas, me puse en contacto con la Dirección de Ordenamiento Urbano, y allí se consolidó mi interés en la ciudad. Aún hoy mantengo contactos con muchos amigos de ese momento, y a otros los recordamos con mucho afecto con los colegas de la Universidad de Buenos Aires, cada vez que me invitan como director o jurado de alguna tesis de la maestría en urbanismo. Sin dudas, el contacto con Pierre George y su círculo fue fundamental para definir mis intereses: más allá de la forma, la ciudad es una cuestión de geografía humana, y todavía hoy lo pienso así cuando leo a Horacio Capel.

Por otro lado, Ilegué a Colombia en 1976, cuando el golpe militar en mi país me empujó a aceptar el refugio que me había ofrecido un excompañero colombiano de la Universidad de La Plata. Y aunque no encontré a aquel excompañero en ese momento, él sí me encontró casi trece años después, cuando ya Bogotá y yo nos habíamos adoptado mutuamente. Los primeros años en Bogotá fueron de descubrimientos constantes. No es fácil pasar de una ciudad de llanura, como lo es La Plata, a una ciudad de montañas, como lo es Bogotá: si mi ciudad natal me enseñó a buscar totalidades en las perspectivas lejanas de la pampa sin límites, Bogotá me enseñaba a mirar los detalles y las visuales cortas, a descubrir lo cercano; y me dejó ver que la vida está en los pequeños fragmentos y se mueve en ambientes reducidos, en redes locales. 
Entre aquellos viajes decisivos, también debo citar algunos realizados durante etapas formativas posteriores, como la que se presentó entre 1986 y 1989, cuando tuve la oportunidad de viajar varias veces a Italia, al ser designado comisionado por Colombia, invitado por la XVII Triennale di Milano, y con el respaldo de la Universidad Nacional de Colombia - que era mi lugar de trabajo- - Algo tuvieron que ver en aquellos viajes los textos que escribía regularmente en la revista Escala, pero nunca imaginé que sería dentro del marco de ese evento donde podría entablar largas y amenas charlas con los personajes que aparecían en mis artículos para Escala: así sucedió con Vittorio Gregotti, Carlo Aymonino, y Hermann Henselmann. Aquella Triennale estuvo dedicada a las ciudades del mundo y al futuro de las metrópolis (Le città del mondo e il futuro delle metrópoli) congregando todos los discursos urbanos del momento. Las reuniones previas de organización fueron una fantástica cátedra de urbanismo, y allí entré en contacto con Aymonino, con quien entendí las alternativas planteadas por la ciudad moderna más allá de la rigidez con la cual la mirábamos desde esta parte del mundo. La ciudad es cuestión de memoria y persistencias; lo decía Aymonino, lo confirmaba Rossi.

En una de esas reuniones previas a la Triennale conocí también al arquitecto alemán Hermann Henselmann (figura 3); tal vez, el último de los grandes arquitectos modernos europeos. Tiempo después recorrí con él la Karl-Marx-Alle, la vieja Stalinallee, avenida berlinesa que yo tanto admiraba, y sobre la que tanto escribí.

Pero lo que más me llamó la atención en aqueIla trienal fue el plan para la periferia de París, de Françoise Labbé y Serge Salat, quien me explicó personalmente su visión sobre aquel mundo de tensiones y fragmentos que conforman la ciudad. Ya no era la continuidad añorada de la ciudad premoderna, sino que se trataba ahora del juego de fragmentos sobre estructuras inestables; juego que yo terminaría de entender a través de los textos de Omar Calabrese, y de Lezioni americane, y de Sei proposte per il prossimo millennio (1988) (Seis propuestas para el próximo milenio), de Italo Calvino —especialmente, el capítulo titulado "Levedad" —.

Finalmente, entre mis viajes formativos debo citar una pasantía de investigación en la Staatsbibliothek, de Berlín, que se hizo posible gracias al Deutscher Akademischer Austauschdienst (DAAD), y que me abrió la puerta a la relación literatura-arquitectura-ciudad, a los textos de Julia Kristeva y a los problemas de significación y sentido en la ciudad. A mi regreso a Bogotá, propuse el seminario "Ciudad escrita" para los estudiantes de arquitectura y artes de la Universidad Nacional de Colombia: contra todo pronóstico, los estudiantes disfrutaron y se emocionaron con la ciudad desde el texto escrito. Entendieron - O mejor, entendimos- que, más allá de la forma que da el significado, son las prácticas con el

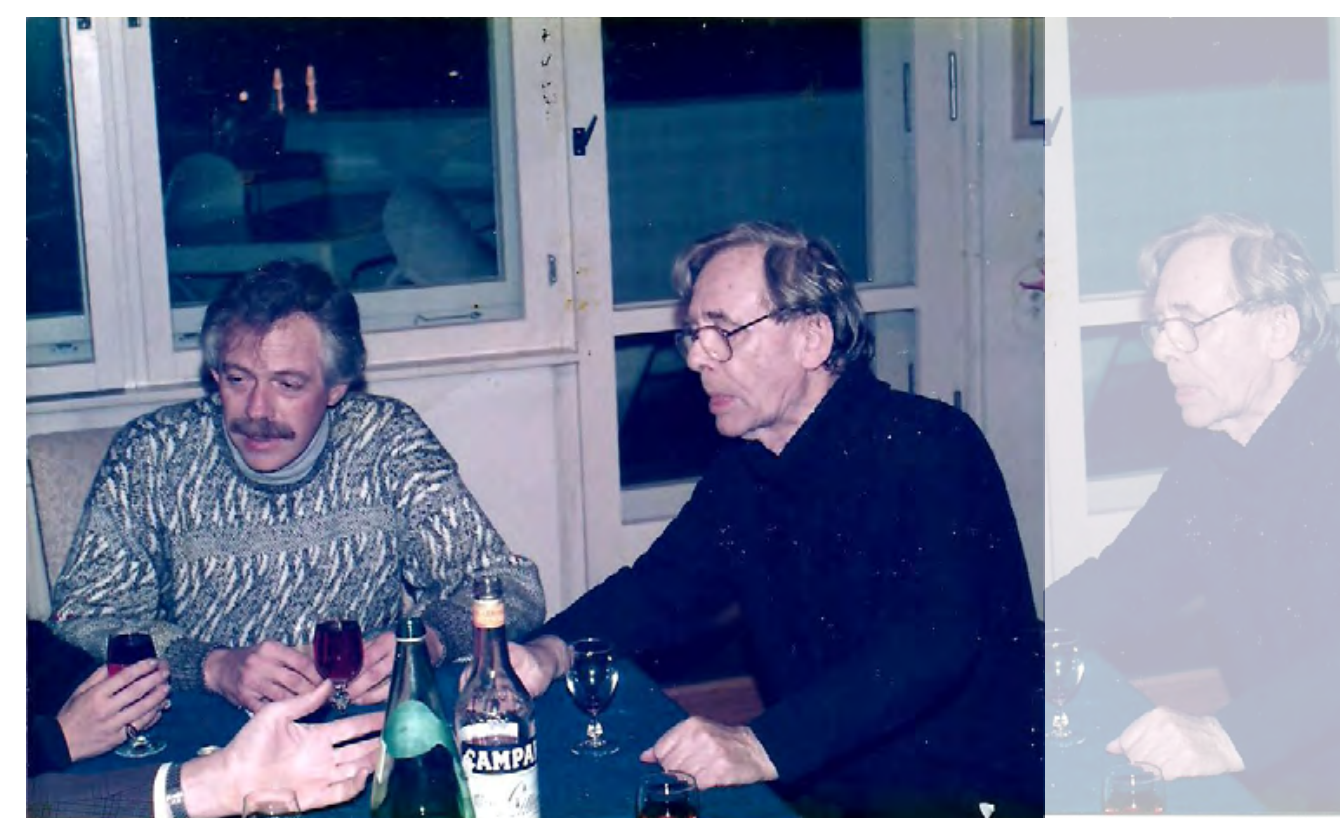

significante "ciudad" las que dan el sentido: el sentido de la vida en la ciudad. De ese seminario surgió el libro Express, arquitectura, literatura y ciudad (1995), con relatos sobre La Plata. En resumen, aquella estadía de estudios en Berlín me permitió también iniciar la investigación que me condujo a la escritura de La plaza, el centro de la ciudad (2002), en el cual abordé diversos aspectos sobre plazas de mi ciudad natal La Plata, de Buenos Aires, de Lima, de Quito y, por supuesto, de Bogotá.

[RCR]: Como estudiante, solo recuerdo el viaje a Honda para levantar, para la clase de historia, la calle de Las Trampas, ubicada en el casco urbano colonial; esta fue una experiencia interesante, porque se unieron dos aspectos que posteriormente encontré en el urbanismo: la calle como un espacio deteriorado por el tiempo, y sus habitantes; la mayoría, prostitutas que trabajan en bares o burdeles. Posteriormente, cuando trabajé en Instituto de Crédito Territorial (ICT), viajé por todo el país, desde La Guajira hasta Pasto, desde Buenaventura hasta Cúcuta, desarroIlando proyectos urbanísticos y arquitectónicos. Había entrado al universo del urbanismo en su componente práctico, trabajando con ingenieros y sociólogos en talleres colectivos y con un jefe senior.

En la hora del almuerzo discutíamos las nuevas tendencias de la arquitectura; entre ellas, principalmente, las ideas de Aldo Rossi y del Team X: ellas nos indujeron a propuestas como el Experimental Kennedy y El Tunal, en las que participé con el diseño urbanístico y arquitectónico; pero faltaba el componente teórico.

[JCDC]: Los viajes de estudios entre los estudiantes de la universidad pública eran muy poco frecuentes. La universidad en esa época no contaba con programas de intercambio consolidados con otros centros educativos. Por otra parte, dependía mucho de la iniciativa y la visión de las facultades. La facultad y los programas de ciencias exactas tenían una más clara tradición y al arquitecto Hermann Henselmann.

Fuente: Archivo J. C. Pérgolis Nota: "Con Henselmann (1905-1995) y con su esposa también arquitecta, descubrí el Berlín recién reunificado; y tuve la oportunidad de escuchar las anécdotas y los chismes que contaban sus colegas sobre aquellos oscuros años de la Bauhaus en el III Reich"
(4) Figura 3. En Berlín, junto 
experiencia en este campo. La Facultad de Artes era muy débil al respecto. Influía de manera notoria, creo yo, el hecho de que no se consideraba necesario que los arquitectos y los artistas tuvieran una formación académica más allá del pregrado. Realizado el pregrado, la formación dependía de la práctica en el oficio, y los estudios de posgrado eran un asunto absolutamente personal. Quienes viajaban eran algunos profesores, que tenían recursos y contactos para emprenderlos. Tuve en algún momento atracción por hacer estudios en Francia, pero no pude concretarlo. Después de algún tiempo de experiencia profesional, e integrado ya en el campo del urbanismo, inicié recorridos por ciudades de Centroamérica y México. Particularmente, tuve interés en visitar ciudades como Antigua y Barbuda, Ciudad de Guatemala, Ciudad de México y los vestigios de los asentamientos de las culturas mesoamericanas.

[AAG]: ¿En qué momento surge su interés en la docencia, y cuáles son las principales razones que lo condujeron simultáneamente a la enseñanza y a la investigación? ¿Cuáles fueron los motivos por los cuales se enfocó principalmente en temas como la historia y la teoría del urbanismo, la historia urbana y la planeación urbano-regional?

Sobre sus temas preferidos, ¿cuáles fueron las escuelas de pensamiento, los autores, y las obras (libros, películas, etc.) que han marcado en diferentes épocas su reflexión intelectual, y que han alimentado su labor como docente e investigador?

[JCPV]: Mi interés en la docencia viene de los profesores que mencioné antes: Jorge Chute y Julio Angel Morosi, mis verdaderos maestros allá en La Plata. Con el profesor Morosi me inicié en 1968 como asistente en Urbanismo II: allí hice mis primeros trabajos de investigación, y allí también aprendí a querer y a maravillarme con las ciudades. Ernst Bloch dijo que "no se muere por un programa que se comprende, se muere por un programa que se ama", y yo me atrevería a decir que no investigamos sobre aquello que comprendemos o intentamos comprender, sino sobre aquello que amamos.

Algo parecido pasa con los libros. Llegamos a amarlos, y eso me ha sucedido desde la primera lectura con textos como Atlas (1994) de Michel Serres; los tres tomos de Les lieux de mémoire (1984, 1986, 1992) (Los lugares de memoria), dirigidos por Pierre Nora; Le città invisibili (1972) (Las ciudades invisibles), de Italo Calvino; The Martian Chronicles (1950) (Crónicas marcianas), de Ray Bradbury; toda la obra de Pierre Levy; los textos sobre lingüística y semiótica de Julia Kristeva, y por supuesto, el mejor libro de historia urbana que he leído: Estambul, ciudad y recuerdos, de Pamuk.

[RCR]: A la docencia llegué por invitación del grupo de arquitectos del ICT, que ya estaban incorporados a la Escuela de Arquitectura de la
Universidad Nacional de Colombia, en el último semestre de 1970. La academia fue el laboratorio para debatir el discurso del movimiento moderno frente a las nuevas propuestas de sus herederos. La arquitectura de Georges Candilis antiguo discípulo de Le Corbusier inspiraba los proyectos del ICT; esta fragmentación, que se oponía a las gigantescas masas representativas del movimiento moderno, hizo carrera en la escuela.

El tema del urbanismo fue consecuente con el trabajo del ICT: era diseño y construcción de proyectos de vivienda a una escala que, en algunos casos, determinaba la forma misma de la ciudad y afectaba el plan regulador existente, como consecuencia de la autonomía que tuvo el ICT como entidad nacional.

De la práctica del urbanismo como un oficio nació la preocupación de conocer sus bases teóricas, sus orígenes y los nuevos conceptos que lo afectaban con el cambio del modelo económico global. Fue esta perspectiva lo que motivó mi viaje al Institut d'Urbanisme, de París, donde me encontré con la investigación como actividad fundamental en la construcción del pensamiento urbanístico, y como base para el trabajo en la planeación de ciudades.

En los años setenta, la Tendenza de la escuela italiana, Christopher Alexander y sus conceptos sobre patrones, la explosión de semiólogos, las preocupaciones sobre una racionalidad en el diseño con su caja negra y caja transparente, todas las reflexiones que surgieron con la crisis del Movimiento Moderno, eran parte del debate académico; pero, realmente, el encuentro con Françoise Choay y la lectura de sus dos principales obras (L'Urbanisme: utopies et réalités y La Règle et le Modèle) marcaron mi accionar en la forma de abordar los problemas urbanos. Hoy día, frente a la restructuración del espacio urbano y regional, producto de las políticas globales y neoliberales, estoy siguiendo los estudios críticos de Edward Soja y David Harvey, y de otros autores latinoamericanos.

[JCDC]: El interés en la docencia brota de dos fuentes: en primer lugar, de mi incursión como dirigente estudiantil en el movimiento por la reforma académica, actividad en la que, de hecho, dicté muchas clases y conferencias, pues reemplazamos a los profesores durante casi un semestre. Tuve reconocimiento como un joven con capacidades pedagógicas. Los estudiantes me entendían, y yo hacía bastantes esfuerzos para preparar mis intervenciones. En segundo lugar, por la experiencia de mi primer trabajo de investigación más o menos consistente destinado a elaborar mi tesis de grado. De esa experiencia sentí, por una parte, que había nacido en mí una idea consistente y que tenía algo que decir a mis contemporáneos; y por otro lado, tenía claro que mi futuro no estaría orientado a abrir un despacho y seguir el camino de los arquitectos diseñadores o constructores, o como un empleado de un estudio de arquitectura. Ese no era mi campo. 
Las corrientes de pensamiento a las que me acerqué fueron, naturalmente, aquellas impregnadas de voces críticas sobre el hecho urbano, sobre la urbanización de la modernidad, la industrialización y el tardocapitalismo, sobre la urbanización en los "países dependientes", así como el pensamiento que revisaba y criticaba los "Treinta años gloriosos" y sus narrativas del progreso y el desarrollo, el libre mercado y el nuevo orden mundial. La crítica marxista de la sociedad y la ciudad industrial fue, sin duda, una de las que me ofrecieron mayores pistas sobre las inquietudes que he señalado. Ya he dicho que los profesores provenientes de Francia y llegados a la facultad en la época en que yo iniciaba mis estudios nos relacionaron con la crítica de la sociología, la filosofía y el urbanismo francés, y a autores como Lefebvre y Choay. Manuel Castells, aunque español, nos fue presentado como hijo de la escuela francesa, y sus dos trabajos La Cuestión urbana (1972) y Movimientos sociales urbanos (1974) empezaron a ser referencia. Por otra parte, estaba muy presente y ejercía influencia la corriente latinoamericana agrupada bajo la divisa de la teoría de la dependencia, que, naturalmente, llevó su narrativa a la interpretación de la urbanización dependiente latinoamericana, que también defendió Castells. Entre sus autores leímos economistas y sociólogos como André Gunder Frank, Ruy Mauro Marini, Theotônio Dos Santos, Enzo Falletto, Celso Furtado, Vânia Bambirra. Una tercera corriente que nos empezó a alimentar fue la de los críticos del movimiento moderno y de la tradición de los CIAM. He señalado también que recibimos las ideas de la crítica de la Tendenza italiana, de la crítica norteamericana y de algunos autores españoles.

En el campo de la historia de la ciudad, yo empecé a indagar sobre autores como Henri Pirenne, Joseph Rykwert, Fernand Braudel y Lewis Mumford, y sobre investigadores de la ciudad latinoamericana, como Serge Gruzinski, José Luis Romero, Ángel Rama y Jorge Enrique Hardoy. Después empecé a leer a otros autores. Debo expresar la influencia en mi forma de ver la ciudad y el planeamiento en autores como Jane Jacobs, Gulio Carlo Argan, Fernando de Terán, la revista Ciudad y Territorio, los latinoamericanos reunidos en torno a Jorge Enrique Hardoy y la Sociedad Interamericana de Planeación (SIAP). En mi etapa más reciente tuve como referentes básicos los aportes de Bernardo Secchi, Edward Soja, David Harvey, Richard Sennett y, particularmente, los trabajos de Peter Hall y Carlos García Vásquez.

Por otro lado, en lo que tiene que ver con la literatura, mis dos novelas preferidas fueron Rayuela (1963), de Julio Cortázar, y más tarde, Los detectives salvajes (1998), de Roberto Bolaño, por su prodigiosa inmersión en dos ciudades que me impactan mucho: París y Ciudad de México. Pero también, el París narrado por Balzac, o el Buenos Aires al que le canta Borges, o la Ciudad de México que arrastra por sus calles y su vida a Carlos Fuentes o a Jorge Volpi, o a Guillermo Fadanelli, o la New York de The Bonfire of the Vanities (1987) de Tom Wolfe, o La Habana de Leonardo Padura, y su detective Mario Conde, en la tetralogía de las Cuatro Estaciones.

La filmografía que eleva como protagonista a la ciudad es también uno de mis referentes favoritos. La reciente Roma (2018), de Alfonso Cuarón, o Amores perros (2000), de Alejandro González Iñárritu, me han dado otra visión profunda de Ciudad de México, así como la New York que pone a actuar Woddy Allen plasma en Manhattan (1979) o en A Rainy Day in New York (2019). De mi época en la universidad, la película que más me impactó como visión audaz de una cultura urbana emergente fue Blow Up (1966), de Michelangelo Antonioni.

[AAG]: Profesor Pérgolis: tres décadas después de su ingreso como estudiante a la Universidad de La Plata, toma usted la decisión de retornar a las aulas en calidad de alumno: entre 1996 y 1998 realiza sus estudios de maestría en el programa de Historia y Teoría del Arte y de la Arquitectura, en la Universidad Nacional de Colombia, sede Bogotá.

¿Cuál es el contexto intelectual en el que se desarrolló esta nueva etapa en su formación académica? ¿Podría contarnos acerca de esta experiencia, cuando usted ya tenía una reconocida carrera como docente e investigador en facultades de arquitectura colombianas?

[JCPV]: Efectivamente, fueron casi cuatro décadas las que transcurrieron. Esta etapa personal, que coincidió con el fin del milenio, estuvo signada por la interpretación; seguramente, motivada por mis muchos años de interés en el psicoanálisis.

Fue entonces cuando comprendí que en la investigación en historia -específicamente, en historia urbana - el hecho de enfrentarse a un documento implica mucho más que la comprobación de un dato: nos exige descubrir qué encierra más allá de su contenido explícito. Entendí que trabajar con una fuente primaria - es decir, contemporánea al hecho o el suceso que estamos investigando- implica conocer el contexto de ese momento —el Zeitgeist-, e implica también interpretar a quién o quiénes lo elaboraron, dónde lo hicieron y con qué intención. Un documento es la puesta en palabras de un suceso, y por lo tanto está afectado por intenciones y deseos de quien lo elaboró. Una aproximación de este tipo a la ciudad nos lleva no solo a interpretar fuentes históricas, sino también, a considerar como fuentes interpretables los comportamientos y las conductas ciudadanas; es decir, las prácticas de los habitantes con el significante "ciudad". En aquella época de mis estudios de maestría, alimentado por las lecturas y la experiencia recogida, comprendí que dicha mirada implicaba entender la ciudad desde una 
semiótica, ya no de las formas significantes, sino de las formas deseadas. Llegaban muchas ideas y muchas líneas de pensamiento. En ese cambio de milenio se manifestó una especial presencia del pensamiento de Jacques Derrida, a través de la obra de los deconstructivistas; influyeron enormemente Peter Eisenman y Zaha Hadid. Pero también trabajamos los textos de Gilles Deleuze, Félix Guattari, y Jean-François Lyotard. Sobe este último, un capítulo titulado "Tomar partido por lo figural", de Discours, Figure (1971) (Discurso y Figura) me explicó muchas cosas sobre arquitectura y ciudad. Igualmente importante para mí resultó ser L'età neobarocca (1987) (La era neobarroca), de Omar Calabrese: un texto muy esclarecedor que trata acerca del pensamiento de finales del siglo XX.

[AAG]: Profesor Carrasco: casi una década después de obtener su diploma de arquitecto, y tras varios años trabajando como docente en la Universidad La Gran Colombia y en asuntos técnicos en el Instituto de Crédito Territorial (ICT), usted decidió instalarse durante un par de años en Francia. ¿Podría describir el contexto en el cual desarrolló sus estudios en la Maestría en Urbanismo, en el seno del Institut d'Urbanisme de Paris? ¿Cuál fue el contexto cultural e intelectual en el que se desarrolló esta segunda etapa en su formación profesional? ¿Cuáles fueron las dificultades o las ventajas que se presentaron durante sus estudios en París? Por favor, háblenos sobre el trabajo de investigación con el cual obtuvo su diploma de urbanista.

[RCR]: Primero debo aclarar que en la Universidad La Gran Colombia solo dicté clases durante un semestre recién me gradué. Terminé Arquitectura en septiembre de 1969, y en septiembre de 1970 estaba vinculado a la Universidad Nacional de Colombia, donde he realizado la actividad docente hasta hoy. En 1978 se presentó el viaje a Francia, con motivo de un proyecto en Chambacú, en Cartagena, muy bien estructurado y elogiado por las directivas del ICT, con las cuales ya tenía un cierto reconocimiento. Con ellas negocié que mi salario fuera para hacer una maestría en urbanismo, lo que convenía a ambas partes en términos de nuevos conocimientos. Aceptada mi solicitud, hablé con Rogelio Salmona para que me orientara a dónde ir, y me dio una carta de presentación para contactar directamente a Françoise Choay.

Las dificultades estaban ligadas al idioma. Mi primer semestre en París estuvo dedicado a clases de francés por la mañana, y por la tarde, en diferentes universidades, y a superar las desigualdades frente a los estudiantes franceses, pues en lo que un francés realizaba en tres días yo me demoraba quince. De resto, todo era ganancia, pues asistía a todos los seminarios, las clases y las conferencias que me era posible: sobre pensamiento estructuralista; sobre la importancia de la geografía en la construcción del cuerpo disci- plinar del urbanismo; sobre la obra de Michel Foucault, y hasta presencié charlas con algunos premios Nobel que visitaban la Université Paris 1. Pero, sobre todo, aproveché el cosmopolitismo de París, y estudié la ciudad industrial del siglo XIX.

Para mí, el Institut d'Urbanisme de Paris, ubicado en aquel momento en Vincennes, tenía el encanto de una señora aristocrática en decadencia, pero ilustrada y reconocida en todo el mundo; sus instalaciones se ajustaban a las condiciones de sus estudiantes tercermundistas o desempleados franceses por la crisis de los años setenta, los profesores representaban el pensamiento de mayo del 68, cuando el neoliberalismo estaba arrasando con el pasado. Fue una extraordinaria experiencia.

La propuesta de mi proyecto de tesis, bajo la dirección de Françoise Choay, consistía en un estudio del texto de las Leyes de Indias, con el objetivo de establecer su pertenencia o no como discurso ordenador del territorio, lo que se desarrolló dentro del marco de los tres paradigmas establecidos por Choay en La Règle et le Modèle (1980) a partir de una comparación con una serie de atributos propios definidos en el corpus disciplinar de cada uno de los paradigmas, que le dan el carácter de textos instauradores por su capacidad de concebir espacios no existentes. Si bien las Leyes de Indias se publicaron después de haber construido las ciudades hispanoamericanas y algunas ordenanzas le dieron su forma en el comienzo, podemos decir que en el texto solo algunos artículos se refieren al ordenamiento urbano en un sentido más regulatorio que conceptual. En consecuencia, el análisis permitió establecer que varios de los atributos propios de los corpus no se cumplían y, por lo tanto, podíamos definirlo tan solo como un texto de carácter realizador más que instaurador.

[AAG]: Profesor del Castillo: transcurrió poco más de una década para que usted retornara a las aulas como alumno: entre 1991 y 1993 realiza sus estudios en Urbanismo, dentro del marco de la joven maestría, creada sobre la base del antiguo Departamento de Urbanística, de la misma universidad. ¿Cuál es el contexto intelectual en el que se desarrolla esta segunda etapa en su formación universitaria? ¿Podría contarnos acerca del programa puesto en marcha por la maestría, y qué tipo de influencias concretas (autores, libros, metodologías, etc.) llegaban por entonces desde otros medios académicos y profesionales europeos, norteamericanos, latinoamericanos (u otros)?

[JCDC]: Ingresé como profesor de la Universidad Nacional de Colombia en la sede de la ciudad de Medellín, y allí estuve durante dos años. Por razones personales (el delicado estado de salud de mi madre), regresé a Bogotá e intenté ser trasladado como docente a la Escuela de Arquitectura de Bogotá, en la que me había 
formado. Quienes dirigían la Facultad de Artes no me habían olvidado, ni a mi papel como dirigente del movimiento por la reforma académica, razón por la cual se opusieron a mi ingreso. Entonces entré a trabajar en los servicios de urbanismo de la ciudad de Bogotá en el Departamento Administrativo de Planeación Distrital, por espacio de doce años. Después de mi corto paso como docente en Medellín, vi la necesidad de hacer estudios de posgrado. Debía ir al exterior, puesto que en Colombia no se habían creado programas de ese nivel en el campo del urbanismo; sin embargo, varias circunstancias me limitaron para irme del país.

Mi desempeño profesional en los servicios de urbanismo de la ciudad de Bogotá me llevó a cuestionar varias de las políticas públicas que se impulsaron desde el gobierno de la ciudad, y ya fatigado en esa experiencia, me enteré de la apertura del primer programa de Maestría en Urbanismo en la Universidad Nacional, al que me presenté; y una vez admitido, renuncié a mi cargo, para satisfacer mi vieja aspiración, a la que me dediqué con mucho entusiasmo.

En aquel momento eran evidentes los resultados y los problemas de la "urbanización acelerada" en el país, que podríamos resumir como una crisis con tres caras: 1) una profunda crisis en la ciudad colombiana, 2) serias deficiencias de la política pública urbana y 3) el notorio debilitamiento del urbanismo como función pública y el predominio de las agendas privadas en el desarrollo urbano.

En dicho contexto se abrió el programa de Maestría en Urbanismo de la Universidad Nacional, al que me vinculé, y obtuve mi título como parte de aquella primera promoción. Este programa fue promovido por un grupo de profesores del Departamento de Urbanismo, que hacía parte de la Escuela de Arquitectura, con un proyecto curricular bastante ecléctico, pero motivado por la preocupación del debilitamiento del urbanismo en la función pública y en la enseñanza en la universidad. Los docentes que impulsaron ese programa estaban influenciados por tres tradiciones distintas: unos, influenciados por la tradición del urbanismo francés y la discusión europea; otros, por la escuela norteamericana, y otros, por la visión "tercermundista".

[AAG]: Profesor del Castillo, treinta años después de su grado como arquitecto, usted decide completar el ciclo de estudios universitarios realizando un Doctorado en Urbanismo: esta vez en otro país, en la prestigiosa Universidad Nacional Autónoma de México [UNAM]. ¿Podría contarnos acerca de las motivaciones para retomar la investigación académica?

[JCDC]: Yo me desempeñaba como coordinador académico de la Maestría en Urbanismo en la UN y quería terminar mi ciclo académico promoviendo la creación de un programa de doc- torado en este campo que no existe en el país. Para ese propósito me relacioné con el programa de doctorado que tiene la UNAM y aceptaron apoyar el proyecto mediante un convenio entre las dos universidades. La UNAM facilitaría la apertura del programa mediante su esquema de cooperación interuniversitaria, aprovechando la facultad y competencia legal de amparo académico e institucional de esa universidad para ser la titular del programa, aportando además el equipo de docentes, becas para los estudiantes y el apoyo logístico para graduar la primera promoción. Cumplida esa primera etapa, se acordaría entre las universidades el traspaso de la continuidad del programa en cabeza de la UN. La idea era que los profesores de la Maestría y los egresados de nuestro programa que quisieran vincularse a realizar los estudios doctorales aprovecharan esta oportunidad. Por obstáculos burocráticos y otras resistencias internas que no vale la pena mencionar, no se pudo llevar a feliz término.

En la Maestría habíamos creado además el grupo de investigación EUT —Estudios urbanos y del Territorio- del cual yo era el coordinador, grupo que había puesto en marcha y realizado varios proyectos de investigación con resultados satisfactorios constituyendo un primer núcleo de investigadores urbanos que podría ser fortalecido con el programa de doctorado. Este fracaso me llevó a presentar mi candidatura individual como aspirante al doctorado de la UNAM y fui aceptado (figura 4).

[AAG]: Hoy, después de una reconocida y brillante carrera profesional de casi medio siglo, ¿cómo percibe usted el presente de la enseñanza de la arquitectura y del urbanismo en Colombia?

Por último, además de los retos que implica actualmente la crisis producida por la pandemia, ¿hacia dónde considera que deben mirar las facultades y las escuelas de arquitectura para evolucionar y mejorar la calidad de sus programas?

[JCPV]: Cuando comencé a trabajar en el medio universitario colombiano, me asombró ver la extraordinaria similitud entre los programas y los métodos de enseñanza vigentes en Colombia
(1) Figura 4. Almuerzo en México tras la sustentación de la tesis doctoral en la UNAM, 2012.

Fuente: Archivo J. C. del Castillo

Nota: En la foto, de izquierda a derecha, con Hira de Gortari, Yohanna Lozoya (sinodal), Constanza Martínez, Germán R. Mejía Pavony (director de tesis), Héctor Quiroz (sinodal), y Juan Carlos del Castillo. Archivo J. C. del Castillo

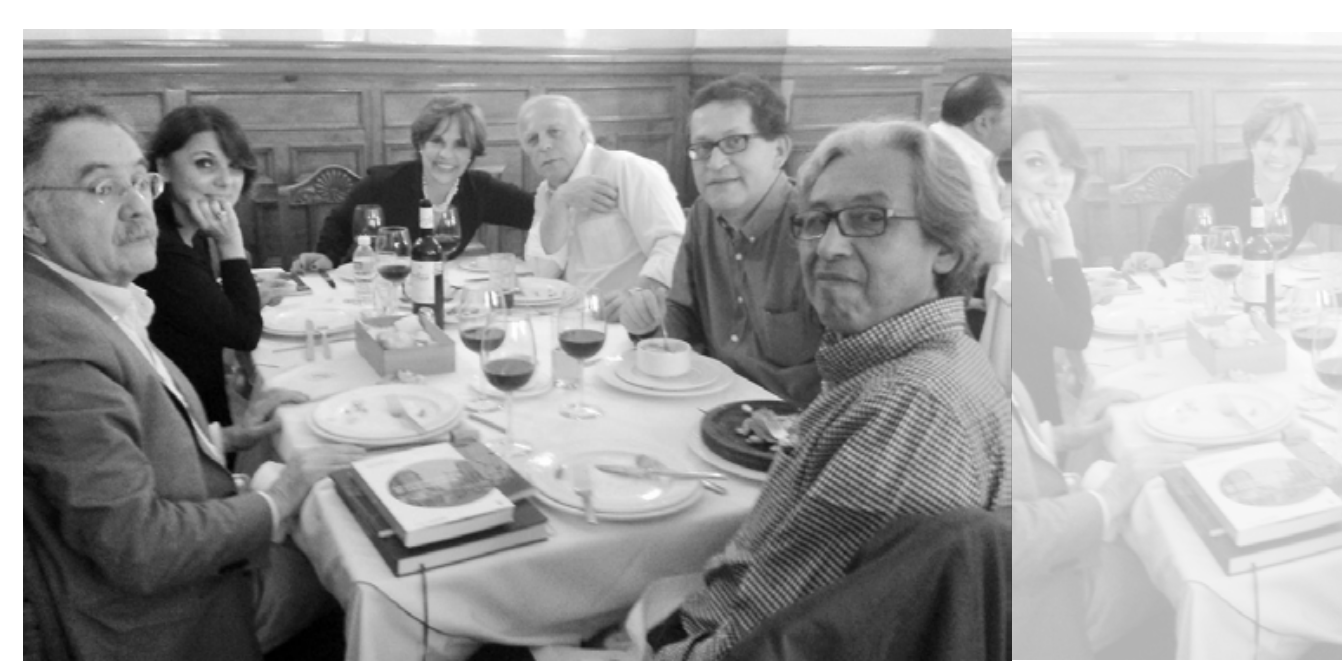




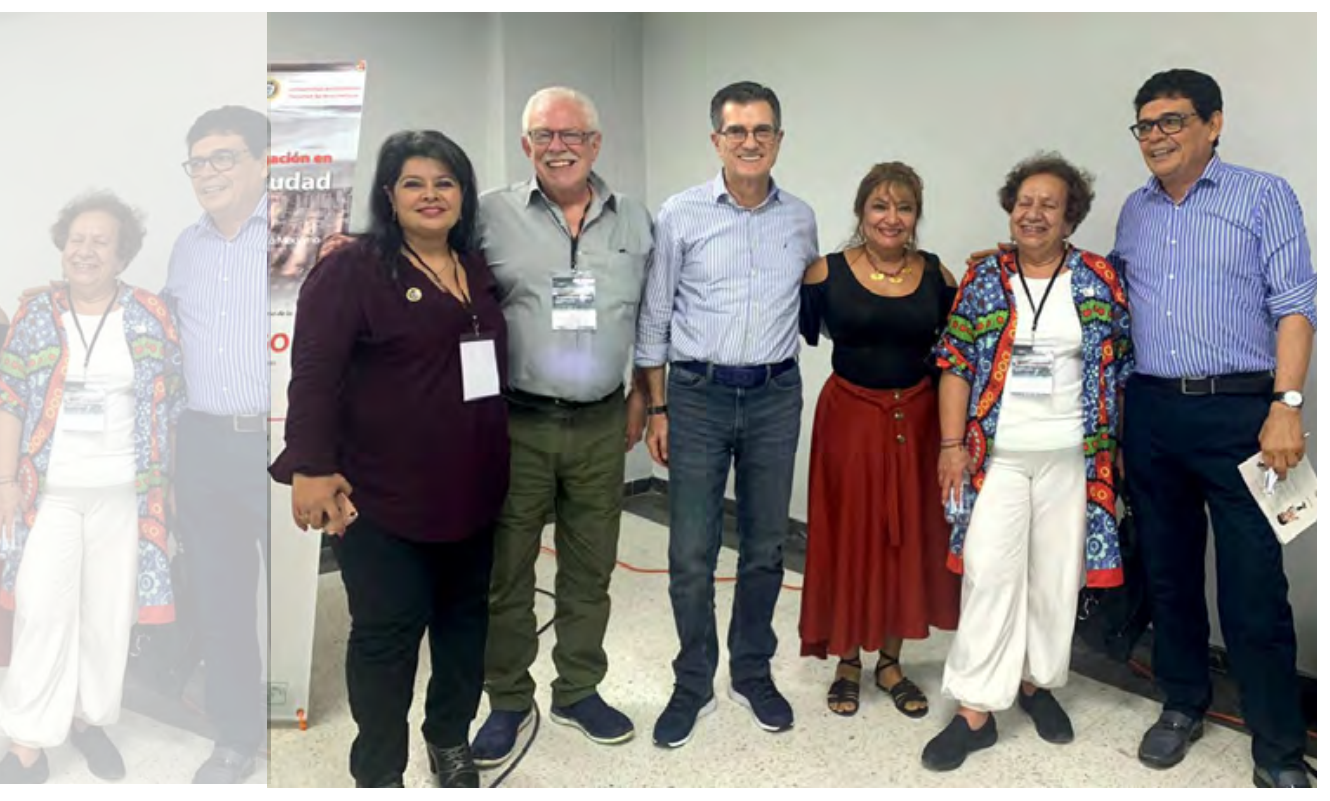

(4) Figura 5. En Barranquilla durante el Seminario Tres décadas de investigación en Arquitectura, ciudad y territorio, 2019

Fuente: Archivo J. C. Pérgolis Nota: En la foto con Marcela Cuéllar (U. del Atlántico,

Barranquilla), Alberto Samudio (U. Tadeo, Cartagena), Silvia Arango (U. Nacional, Bogotá), Ignacio Consuegra (U. Simón Bolivar, Barranquilla) y Argentina. Evidentemente, los modelos pedagógicos de la Bauhaus y la arquitectura del movimiento moderno habían alcanzado una enorme difusión internacional y eran la referencia obligada en diferentes partes del mundo. Al iniciar la década de 1980, se distinguían claramente dos líneas de trabajo: una que se acercaba a la crítica a la ciudad moderna e intentaba recuperar valores de la ciudad tradicional, y otra que veía el edificio, la obra arquitectónica, como un objeto aislado, como un artefacto. En los años noventa, el discurso de la deconstrucción pasó por todas nuestras facultades; la idea del edificio-artefacto continuó y la reflexión se alejó cada día más de la ciudad.

Desde mi punto de vista, es preocupante que la enseñanza actual en las facultades de arquitectura se acerque demasiado a lo técnico y se formen profesionales que conocen muy bien su oficio - excelentes diseñadores-, pero que parecen desconocer o despreciar la importancia que tienen las particularidades de la vida cotidiana. Asombra ver la arquitectura que hoy muestra la publicidad de finca raíz: edificios de excelente diseño y calidad constructiva rodeados de paisajes verdes ideales que borran la ciudad que los rodea, situándolos en sitios abstractos. La ciudad ya no es atractiva para las ventas, y así parecen entenderlo nuestros egresados.

En la enseñanza del urbanismo ocurre algo parecido: interesan más las cifras que las vivencias; sin embargo, el mundo se comprende mejor a través de relatos y de anécdotas que muestran la vida, que de estadísticas que cuantifican la existencia a través de cifras y porcentajes: los tan sonados "indicadores". La arquitectura genera los espacios para la existencia (el espacio existencial definido por Christian Norberg-Schulz) crea lugares; es decir, hace posibles los acontecimientos para que el espacio abstracto se convierta en lugar para la vida.

Arquitectura y urbanismo, o construir y hacer ciudad, no son actividades separadas: un arquitecto renacentista o neoclásico concebía arquitectura, y al mismo tiempo hacía ciudad, sin pensar que eran quehaceres diferentes; trabajaba con la misma materia prima, en distintas escalas, con reflexiones propias de cada una, pero con un objetivo común.

En estos días se habla mucho, en las facultades de arquitectura, de la ciudad del futuro, de la ciudad de la pospandemia, como una determinante en la concepción de la ciudad. Este es el resultado de entender a la ciudad sin la comunidad que la habita, sin ver que a la ciudad hay que pensarla desde lo social antes que desde la arquitectura y el urbanismo, y que las situaciones críticas que muestra la pandemia tienen que ver más con los comportamientos sociales que con la forma física. La ciudad de la pospandemia.

La ciudad es el territorio de la comunidad; sin ella no hay ciudad. Hoy pensamos $-\mathrm{y}$ es tema de debate en la academia- que la comunidad puede hacerse desde lo virtual; pero para lograr eso tendríamos que compartir una historia y un devenir en común que fortalezcan el arraigo, y ya no solo tener intereses y gustos que promueven encuentros en la red. Sin arraigo a un lugar no hay comunidad ni ciudad, por lo cual ese territorio de la comunidad virtual no tendrá forma o, por lo menos, no tendrá forma de "ciudad" como la conocemos nosotros, ni, incluso, como intentó tenerla la ciudad moderna, la de los CIAM, la de las cuatro funciones.

Si la ciudad es la expresión de una comunidad organizada y localizada en un territorio, la ciudad del futuro será la no-ciudad: sin territorio, dispersa en la virtualidad de las redes, pero sin comunidad. Tal vez será el resultado de infinidad de individuos que establecerán infinidad de conexiones, opciones y vecindades en la red. En ese mundo futuro, Pierre Lévy nos habla de una inteligencia repartida en todas partes, en la red, "Una inteligencia colectiva en la que nadie lo sabe todo, todo el mundo sabe algo, todo el conocimiento está en la humanidad".

Vale la pena preguntarse entonces: ila virtualidad de la ciudad en la red, aleatoria y dispersa, es el nuevo paisaje de un territorio, ocupado ya no por individuos, sino por la humanidad como una totalidad? Ante eso, y con la gran experiencia de virtualidad que vivimos en estos días de pandemia, ¿qué ciudad se concibe y se enseña en las facultades y las escuelas de arquitectura?

Para finalizar, retomo la frase de Ernst Bloch, que cité anteriormente: "No se muere por lo que se comprende sino por lo que se ama". La investigación sobre ciudad debe partir de la ciudad que amamos, y ese amor por lo colectivo —que es la ciudad- debe ser el objeto de enseñanza y de investigación en la academia. Si no es así... dudemos del resultado (figura 5).

[RCR]: El urbanismo, como disciplina en Colombia, se enfrenta a una crisis de credibilidad, por lo poco efectivos que han sido los planes de ordenamiento territorial frente a las demandas de la 
comunidad; sus objetivos, diseñados desde la concepción urbanística, no alcanzan a realizarse ni en el $40 \%$; las fuerzas del mercado siguen dominado las operaciones urbanas; abogados y economistas parecen tener el poder de definir cómo organizar el territorio anulando las pretensiones de los urbanistas en términos de sostenibilidad y calidad de vida. De manera que la academia seguirá siendo un laboratorio para experimentar nuevas soluciones para los problemas urbanos y ponerlas a consideración de las comunidades y los gestores de los planes de ordenamiento, para que en algún momento tengan instrumentos de negociación con los agentes privados que den un cierto equilibrio en el ordenamiento del territorio.

Ahora bien, lo positivo de la pandemia ha sido el encuentro de intelectuales, emprendedores y la población en general con las nuevas tecnologías de las comunicaciones, lo que, seguramente, va a generar cambios en el uso de los espacios universitarios y en los programas académicos, los cuales necesariamente van a profundizar $-\mathrm{O}$ a iniciar- su internacionalización. Con esto se acelerarán los procesos del conocimiento en cada una de las áreas y, por consiguiente, evolucionarán a un estado de mayor calidad.

[JCDC]: Es una pregunta difícil de responder. No podría aventurar una opinión sobre la enseñanza actual de la arquitectura y del urbanismo en Colombia. Me limitaría al ámbito de mi universidad. He sido testigo de un esfuerzo sincero de muchos de mis colegas por identificar las demandas que hoy tiene o debería tener el país al respecto, y la universidad pública en particular. También he visto esfuerzos por encontrar una pedagogía adecuada para formular las preguntas pertinentes.

Uno percibe en el ambiente que los estudios de arquitectura y las empresas constructoras demandan jóvenes con habilidades y destrezas en el manejo de tecnología y software para las tareas subalternas. Por supuesto, esta siempre ha sido una demanda del mercado. Sabemos que el mercado requiere y demanda un perfil de profesionales, y hay un tipo de escuela que los produce. Pero, ¿se responde igualmente a las necesidades de la sociedad en la que estamos inmersos, y de las ciudades en las que vivimos?
Creo que la actual crisis sanitaria, enlazada con una crisis más sistémica y profunda, está planteando y exigiendo respuestas urgentes. En general, yo me inscribo en una corriente que reclama más humildad, modestia y sinceridad para responder a estos desafíos. No comparto la arrogancia, la soberbia y las certezas de algunos discursos actuales, sobre el futuro de las "ciudades inteligentes", las poderosas tecnologías, los gigantes informáticos manejando de manera eficiente y certera la seguridad, la movilidad, la salud, la biología, la rutina, el hábitat y la vida simbólica de los seres humanos, entendidos como consumidores y electores. La promesa de ir a un "mundo virtual" al cual podremos acceder desde un triste y mísero cubículo, pero pagando suscripciones a plataformas y aplicaciones, no la veo como solución para la "ciudad de la sobrevivencia" que, en nuestro caso y en muchos otros sitios del mundo, nos puso de presente la pandemia.

Entonces, ¿hacia dónde hay que mirar? Creo que hay que reflexionar también en que desmovilizar, desmercantilizar, descontaminar, desarmar y decrecer no son ideas para la destrucción y el retroceso. Son ideas que nos pueden y nos deben llevar a explorar no solo en una ecología de respeto a la naturaleza, sino también, en una ecología de la convivencia y una ecología íntima del ser y de su espacio vital (figura 6).

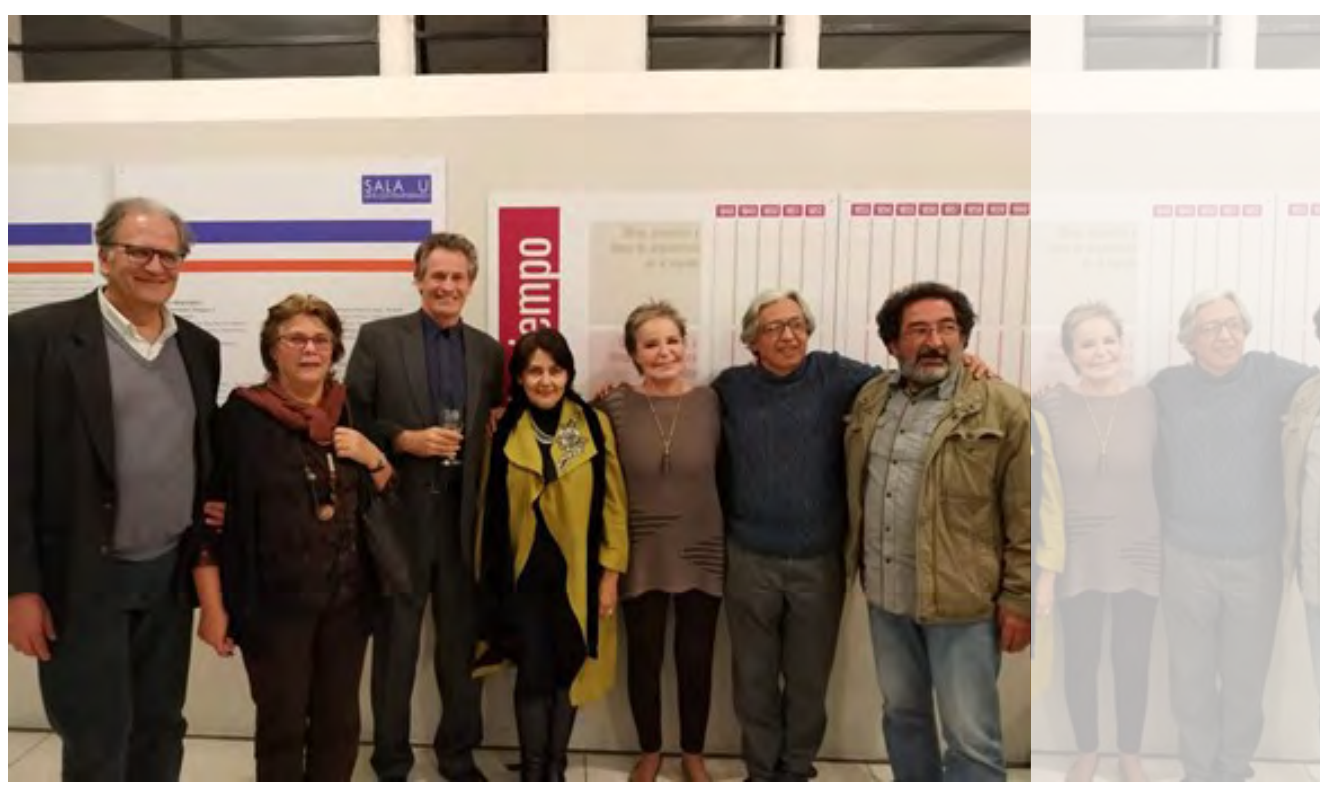

(1) Figura 6. Reunión en la UN en homenaje a la labor docente de Juan Carlos del

Castillo, junto con compañeros

Fuente: Archivo J. C. del Castillo

Nota: De izquierda a derecha: Rodrigo Cortés Solano,

Mónica Guzmán, Federico Demmer Colmenares, Martha Madrid, Gloria Barney, Juan Carlos Del Castillo y Carlos García. colegas desde 1970.

\section{Referencias}

Alexander, C. (1965). A City is not a tree (I - II), Architectural Forum, 122(1), 58-62. https://www.patternlanguage.com/archive/ cityisnotatree.html

Angulo Flórez, E. (1986). AA.VV., (1986), Cincuenta años de arquitectura. Universidad Nacional de Colombia, Bogotá, 19361986, Bogotá. Asociación de Arquitectos de la Universidad Nacional de Colombia.

Avila Gómez, A, Muñoz Lozano, Y, Porraz Castillo, M. (18 y 19 de noviembre de 2020). Circulación de modelos en la enseñanza de la arquitectura, el urbanismo y la construc- ción de la ciudad. Francia y América Latina, siglos XIX-XX. $1^{\circ}$ Seminario Internacional "Transferencias/Interferencias", Université Paris 1 Panthéon-Sorbonne / Pontificia Universidad Católica de Chile / Ecole Nationale Supérieure d'Architecture de Versailles [https://transferts.hypotheses.org/129]

Calabrese, O. (1987). L'età neobarocca. Laterza. (La era neobarroca. Ediciones Cátedra, 1989).

Calvino, I. (1988). Sei proposte per il prossimo millennio. Garzanti. (Seis propuestas para el próximo milenio. Ediciones Siruela, 1989). 
A Portada: Catedral de Notre Dame de Paris durante los trabajos de reparación en octubre de 2020 Fotografía: Arquitecto Andrés Avila Gómez (octubre, 2020)
(A) Orientación editorial

\section{Enfoque y alcance}

La Revista de Arquitectura (Bogotá) ( (ISSN 1657-0308 Impresa y E-ISSN 2357-626X en línea) es una publicación científica seriada de acceso abierto, arbitrada mediante revisión por pares (doble ciego) e indexada, en donde se publican resultados de investigación originales e inéditos.

Está dirigida a la comunidad académica y profesional de las áreas afines a la disciplina. Es editada por la Facultad de Diseño y el Centro de Investigaciones (CIFAR) de la Universidad Católica de Colombia en Bogotá (Colombia).

La principal área científica a la que se adscribe la Revista de Arquitectura (Bogotá) según la OCDE es:

Gran área: 6. Humanidades

Área: 6.D. Arte

Disciplina: 6D07. Arquitectura y Urbanismo

También se publican artículos de las disciplinas como 2A02, Ingeniería arquitectónica; 5G03, Estudios urbanos (planificación y desarrollo); 6D07, Diseño.

Los objetivos de la Revista de Arquitectura (Bogotá) son:

- Promover la divulgación y difusión del conocimiento generado a nivel local, nacional e internacional

- Conformar un espacio para la construcción de comunidades académicas y la discusión en torno a las secciones definidas.

- Fomentar la diversidad institucional y geográfica de los autores que participan en la publicación.

- Potenciar la discusión de experiencias e intercambios científicos entre investigadores y profesionales.

- Contribuir a la visión integral de la arquitectura, por medio de la concurrencia y articulación de las secciones mediante la publicación de artículos de calidad.

- Publicar artículos originales e inéditos que han pasado por revisión de pares, para asegurar que se cumplen las normas éticas, de calidad, validez científica, editorial e investigativa.

- Fomentar la divulgación de las investigaciones y actividades desarrolladas en la Universidad Católica de Colombia.
Palabras clave de la Revista de Arquitectura (Bogotá): arquitectura, diseño, educación arquitectónica, proyecto y construcción, urbanismo.

Idiomas de publicación: español, inglés, portugués y francés.

Título abreviado: Rev. Arquit.

Titulo corto: RevArq

\section{Políticas de sección}

La revista se estructura en tres secciones correspondientes a las líneas de investigación activas y aprobadas por la institución, y dos complementarias, que presentan dinámicas propias de la Facultad de Diseño y las publicaciones relacionadas con la disciplina.

Cultura y espacio urbano. En esta sección se publican los artículos que se refieren a fenómenos sociales en relación con el espacio urbano, atendiendo aspectos de la historia, el patrimonio cultural y físico, y la estructura formal de las ciudades y el territorio.

Proyecto arquitectónico y urbano. En esta sección se presentan artículos sobre el concepto de proyecto entendido como elemento que define y orienta las condiciones proyectuales que devienen en los hechos arquitectónicos o urbanos, y la forma como estos se convierten en un proceso de investigación y nuevo de conocimiento. También se presentan proyectos que sean resultados de investigación, los cuales se validan por medio de la ejecución y transformación en obra construida del proceso investigativo. También se contempla la publicación de investigaciones relacionadas con la pedagogía y didáctica de la arquitectura, el urbanismo y el diseño.

Tecnología, medioambiente y sostenibilidad. En esta sección se presentan artículos acerca de sistemas estructurales, materiales y procesos constructivos, medioambiente y gestión, relacionados con los entornos social-cultural, ecológico y económico.

Desde la Facultad. En esta sección se publican artículos generados en la Facultad de Diseño, relacionados con las actividades de docencia, extensión, formación en investigación o internacionalización, las cuales son reflejo de la dinámica y de las actividades realizadas por docentes, estudiantes y egresados; esta sección no puede superar el $20 \%$ del contenido.

Textos. En esta sección se publican reseñas, traducciones y memorias de eventos relacionados con las publicaciones en Arquitectura y Urbanismo.
A Frecuencia de publicación

Desde 1999 y hasta el 2015, la Revista de Arquitectura (Bogotá) publicó un volumen al año, a partir del 2016 se publicarán dos números por año en periodo anticipado, enero-junio y julio-diciembre, pero también maneja la publicación anticipada en línea de los artículos aceptados (versión Post-print del autor).

La Revista de Arquitectura (Bogotá) se divulga mediante versiones digitales (PDF, HTML, EPUB, XML) e impresascon un tiraje de 700 ejemplares, los tiempos de producción de estas versiones dependerán de los cronogramas establecidos por la editorial.

Los tiempos de recepción-revisión-aceptación pueden tardar entre seis y doce meses dependiendo del flujo editorial de cada sección y del proceso de revisión y edición adelantado.

Con el usuario y contraseña asignados, los autores pueden ingresar a la plataforma de gestión editorial y verificar el estado de revisión, edición o publicación del artículo.
(A) Canje

La Revista de Arquitectura (Bogotá) está interesada en establecer canje con publicaciones académicas, profesionales o científicas del área de Arquitectura y Urbanismo, como medio de reconocimiento y discusión de la producción científica en el campo de acción de la publicación.

Mecanismo

Para establecer canje por favor descargar, diligenciar y enviar el formato: RevArq FP20 Canjes

Universidad Católica de Colombia
(202I, enero-junio). Revista de
Arquitectura (Bogotá), 23(I),
I-I24. Doi: 10.14718

ISSN: I657-0308
E-ISSN: 2357-626X
Especificaciones:
Formato: $34 \times 24 \mathrm{~cm}$
Papel: Mate II5 g
Tintas: Negro y policromía

Contacto

Dirección postal:

Avenida Caracas No. 46-72

Universidad Católica de Colombia

Bogotá D. C., Colombia

Código postal: 111311

Facultad de Diseño

Centro de Investigaciones (CIFAR)

Sede El Claustro. Bloque "L", 4 piso

Diag. 46A No. 15b-10

Editor, Arq. César Eligio-Triana

Teléfonos:

+57 (1) $3277300-3277333$

Ext. 3109; 3112 o 5146

Fax: +57 (1) 2858895
Correo electrónico:

revistadearquitectura@ucatolica.edu.co cifar@ucatolica.edu.co

Página WEB:

www.ucatolica.edu.co

Vínculo Revistas científicas

http://publicaciones.ucatolica.edu.co revistas-cientificas

https://revistadearquitectura.ucatolica.edu.co/ 
Reflexiones en torno a la enseñanza de la arquitectura y el urbanismo en Colombia. Conversaciones con Juan Carlos

m. Pérgolis Valsecchi, René Carrasco Rey y Juan Carlos del

¿ Castillo

Reflections on the teaching of architecture and urban planning in Colombia. Conversations with Juan Carlos Pérgolis Valsecchi, René Carrasco Rey y Juan Carlos del Castillo

웅

La experiencia de caminar en ciudades latinoamericanas

The experience of walking in Latin American cities

Movilidad urbana de la población en la ciudad de Encarnación * Paraguay. Desarrollo urbano y gestión ambiental

$m$ Urban mobility of the population in the city of Encarnación, Paraguay.

这

ษั

La vivienda adecuada financiada según el ingreso.

El discurso de las Naciones Unidas

பं

La arquitectura frente a las innovaciones pedagógicas.

Pervivencia y resignificación de la Escuela Nueva en el Cono Sur Architecture facing the pedagogical innovations. Survival and resignification of the New School in the Southern Cone

Aporte de las competencias investigativas a la integración de saberes curriculares.

Una visión en el escenario de aprendizaje del diseño

arquitectónico

Contribution of research competencies to the integration of curricula knowledge. A vision in the architectural design learning scenario

Adobe como saber ancestral usado en construcciones

N autóctonas de Pore y Nunchía, Casanare (Colombia)

j. Adobe as an ancestral knowledge used in autochthonous constructions $\stackrel{4}{\longleftarrow}$

Paisaje construido y sustentabilidad urbana: huellas

$œ$

El Plan de Transformación de Osorno

Built landscape and urban sustainability: Identity prints of the modern landscape. The Osorno Transformation Plan

Indicadores de sostenibilidad social y su relación con el

$\hat{a}$

ن்

노 caso de estudio en Cuenca (Ecuador)

ن

Confort térmico en vivienda social multifamiliar de clima cálido en Colombia

느 Thermal comfort in multi-family social housing in a warm climate in ن் Colombia
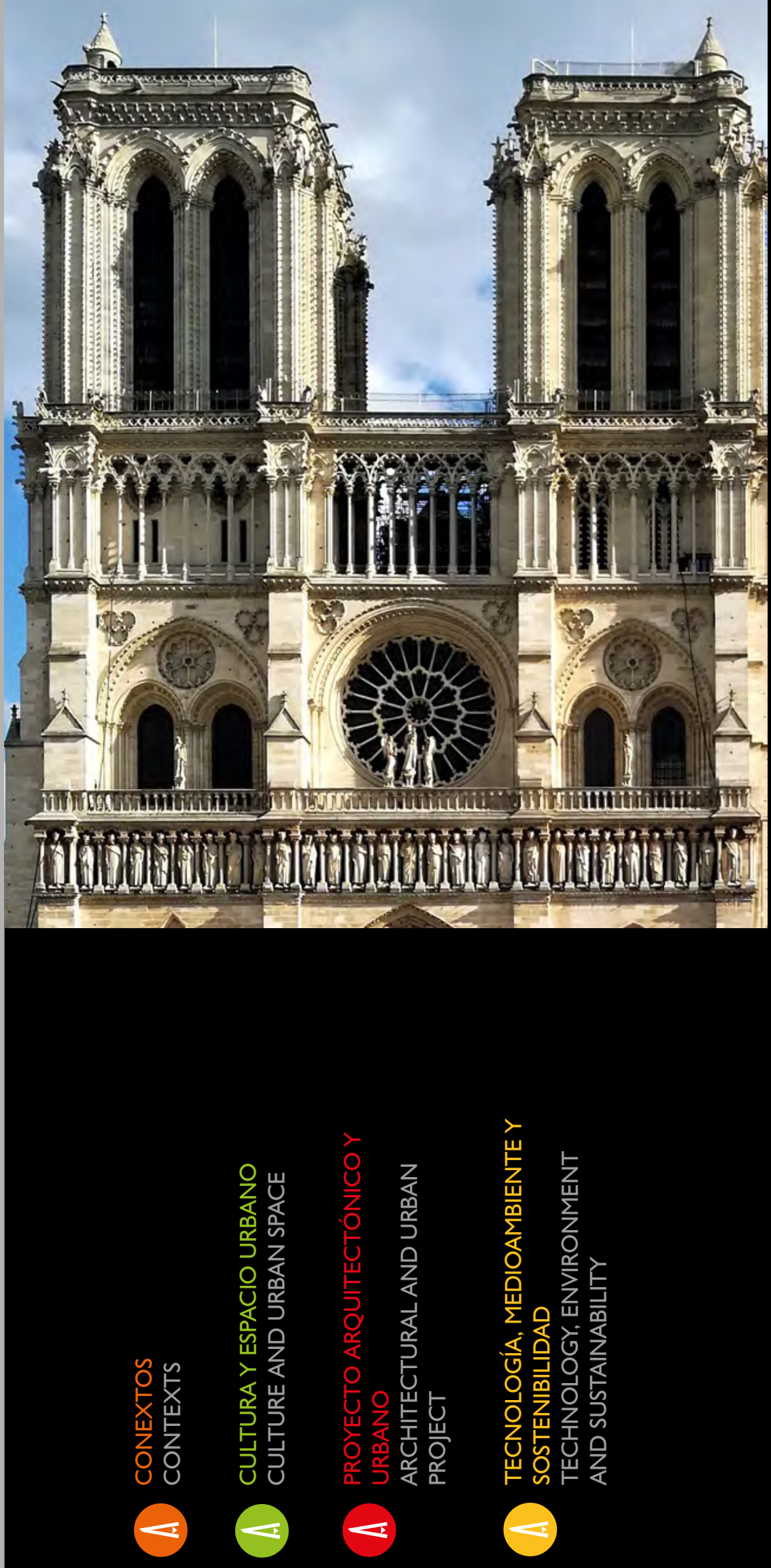

La Revista de Arquitectura es de acceso abierto, arbitrada e indexada y está presente en:
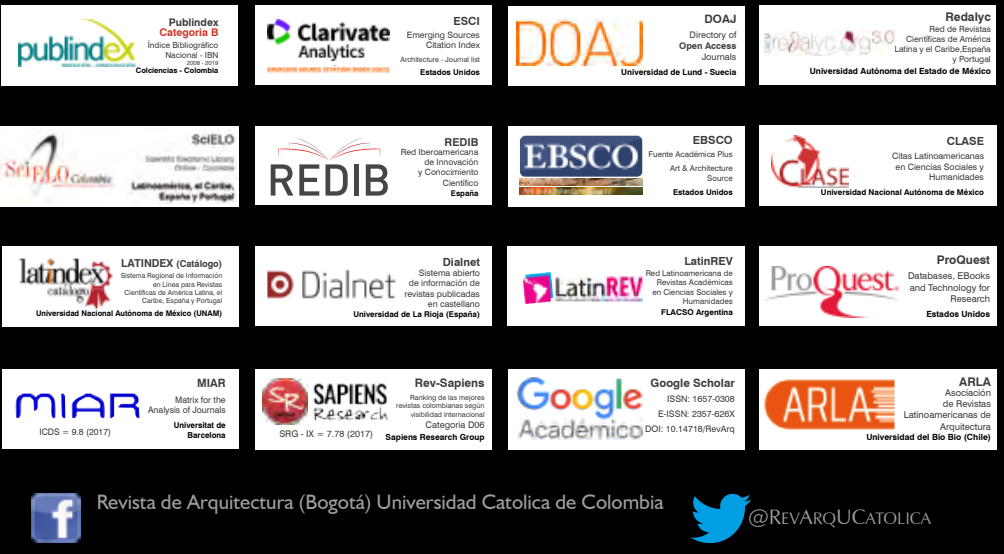

8
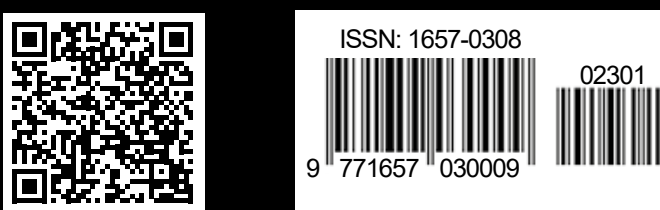